\title{
What role can information play in improved equity in Pakistan's irrigation system? Evidence from an experimental game in Punjab
}

\author{
Andrew Reid Bell ${ }^{1}$, M. Azeem A. Shah ${ }^{2}$, Arif Anwar ${ }^{2}$ and Claudia Ringler $^{3}$
}

\begin{abstract}
The Indus Basin Irrigation System suffers significant inequity in access to surface water across its millions of users. Information, i.e., monitoring and reporting of water availability, may be of value in improving conditions across the basin, and we investigated this via an experimental game of water distribution in Punjab, Pakistan. We found evidence that flow information allowed players to take more effective action to target overuse, and that overall activities that might bring social disapproval were reduced with information. However, we did not find any overall improvement in equity across the system, suggesting that information on its own might not be sufficient to lead to better water distribution among irrigators.
\end{abstract}

Key Words: framed field experiment; irrigation; Pakistan

\section{INTRODUCTION}

The massive irrigation system of Pakistan's Indus Basin, i.e., the Indus Basin Irrigation System (IBIS), is a network of thousands of kilometers of canals, distributaries, and narrow watercourses that spreads the flow of the Indus across vast areas of the provinces of Punjab and Sindh (Khan 2009). The system is gravity fed, with flow allocation through the system dictated by slope, channel size, and geometry. It represents the far end of the spectrum, ranging from small locally managed irrigation systems to large publicly financed systems, spanned by irrigation developments in South and Southeast Asia (Barker and Molle 2004). As a pole in this spectrum, it provides an important case to examine both the benefits and problems that may befall such large and inflexible infrastructural investments. Begun on the Ravi River, in what is now India, in 1886 (Bengali 2009), the system has experienced more than a century of development, maintenance, depreciation, user manipulation, and changes in agricultural practice; current cropping intensities of $150 \%$, where $100 \%$ implies 1 crop per year covering the whole area, are more than double the design criteria for much of the system (Khan 2009). Coupled with a lack of accounting for losses attributable to seepage (Kahlown and Kemper 2005), and to problems of poor drainage and salinity (Qureshi et al. 2008), the result is a buildup of inequitable access to surface water across the system's millions of users.

Considerable investment has been made by Pakistan and donors such as the World Bank in recent decades to address, among other issues, the problem of inequity. Most notable has been the effort, now nearly 2 decades in process, of irrigation management transfer (IMT), promoting a mode of participatory irrigation management that establishes a multitiered system of governance responsibility. Interest in IMT is widespread in Asia; Mukherji et al. (2009) document and evaluate 108 different cases of IMT across Asia, with the majority of cases (74) in South and Southeast Asia. In Pakistan's case, the structure of the reform is as follows: at the level of the watercourse, from which individual farms draw water in a fixed-turn (warabandi) schedule, water user associations, or khal panchayats (KPs), are formed with the purpose of addressing watercourse-level maintenance issues and conflicts. KPs elect a chairman who represents them in Farmers'
Organizations (FOs), formed at the distributary level and holding responsibility for maintenance and conflict issues at the distributary level, as well as for collection of water use fees (abiana; Asrar-UlHaq 2010). FOs in turn send representatives to area water boards (AWBs) formed for each canal command area. The progress of the reform and the performance of AWBs, FOs, and KPs has been well reviewed in recent literature (e.g., Latif and Tariq 2009, World Bank 2010, Ghumman et al. 2011), and we will not belabor this topic. As a simple summary, reform has been established in less than one-fifth of canal commands across Punjab and Sindh, attributable in no small part to resistance from the provincial irrigation departments (PIDs), which stand to lose authority through the reform; performance issues of FOs across Sindh and Pakistan include yet-persistent inequity in water distribution and a low and declining willingness to pay abiana (Memon 2006, U1 Hassan 2009, Asrar-UlHaq 2010).

One ingredient in improving conditions across the basin, and in other public schemes across the region, may be information, i.e., monitoring and reporting of water availability through the irrigation system. Awareness of the higher level constraints on water supply that shape availability in lower level distributaries might provide some incremental improvement of willingness to pay, as the link between abiana and system maintenance is made more transparent; this in turn could facilitate the gradual scaleup in cost recovery suggested by Briscoe and Qamar (2005). Additionally, disclosure of watercourse off-take volumes along distributaries may provide FOs with useful input to conflict resolution and increase the cost of illegal manipulation of offtakes.

We begin inquiry into the potential value of information in the IBIS via an experimental game of water distribution played by farmers in Punjab province, a novel application to members of a massive publicly financed irrigation system of methods typically explored in smallholder irrigation systems. This experiment is part of a larger project being undertaken jointly by the International Food Policy Research Institute and the International Water Management Institute that includes a pilot study of flow monitoring and reporting in the Hakra command area of Punjab. The broad goal of these efforts is to evaluate the potential impacts

${ }^{1}$ New York University, Department of Environmental Studies, ${ }^{2}$ International Water Management Institute, ${ }^{3}$ International Food Policy Research Institute 
that improved information can have on farmer decisions and behavior, and thus on system-level efficiency and equity outcomes.

\section{The role of information in shared water resources}

The importance of resolving information asymmetries in shared resource problems is well studied. Standing out among others, Elinor Ostrom's work has shown it to be a critical component of establishing rules and norms for sustainable collective action and self-governance in smallholder resource systems (e.g., Ostrom 1992, 2000). The major public irrigation systems of South Asia differ in scale from the self-governed systems that are the focus of Ostrom's work, but information remains important. For example, within the polycentric system of participatory irrigation management in India, communication regarding flow and water supply constraints between irrigation agencies and farmer's groups is critical to comanagement (Meinzen-Dick et al. 2002). In Pakistan, the movement toward participatory irrigation management is yet under development, and issues of head-to-tail inequity persist across watercourse and distributary scales. Farmers at the heads of distributaries or watercourses have the advantages of not only better water access but also more complete information regarding water supply (Azam and Rinaudo 2004).

With IMT in its current state of development in Pakistan, we wish to understand the potential contribution that flow information alone can make to improving water outcomes. Flow gauges are not commonly in use in Pakistan, and where present, they may be degraded beyond use to farmers, KPs, or FOs (e.g., Azam and Rinaudo 2004). The purpose of the current study and others within our larger project is to evaluate the role that such gauges could play in improving equity and efficiency outcomes in the IBIS. In so doing, we hope to begin to provide an understanding of the possible tools for changing performance in large public irrigation systems, as has been better articulated previously for smaller community-managed systems in the literature.

\section{Experimental approaches in irrigation systems}

There are several salient examples in the literature of field and lab experiments using games in an irrigation context. D'Exelle et al. (2012) developed a paper-based, two-player game for members of small, self-governed irrigation systems in Tanzania. The structure of their game derived from the archetype of a repeated ultimatum game; the upstream player made a decision about how many hours to keep his irrigation gate open, during which water capture was complete and no water flowed downstream, and the downstream player was provided a mechanism to punish the upstream player for making inequitable choices. Production payoffs were an s-shaped threshold function of hours of water used. Across treatments of water abundance and scarcity, the authors found a preference for equity, as opposed to fear of punishment, that best explained the patterns of water sharing and alternating water use under the scarcity observed in the experiments.

In a series of experiments in the field, using pencil and paper, and in the lab, using computers, another research effort led by Cardenas and Janssen developed a computer-based irrigation game for five players that combined a public-goods game with the upstream-downstream water distribution game (Janssen et al. 2011, Cardenas et al. 2013). In this setup, players chose a resource contribution to make toward irrigation infrastructure maintenance; this captured the public-good nature of small, self- governed irrigation systems in which farmers reap benefits from their joint efforts in maintaining system performance. The total amount of water available for the round was a function of the total contribution from all players, which was then available to the players in a timed round during which the players extracted water by opening and closing their irrigation gates. Players upstream had better access to water resources, creating a resource problem for downstream users if upstream gates were not left closed long enough for sufficient resources to travel to tail-end users downstream. The experiment added the additional step of allowing players to choose a new governing rule, basing water access on a lottery, rotation, or water rights, after 10 rounds. The authors found lower social efficiency over repeated rounds as participants contributed less in the public-goods games, but they observed better distributions from upstream to downstream in the second half of their experiments, after players selected their own rules for governance.

These examples share a common focus on small irrigation systems in which contribution by members can lead clearly to improved outcomes and in which mechanisms exist for punishing abuse of the system over repeated rounds, such as by withholding contributions to maintenance. The realities in large-scale publicly funded irrigation projects are different because the linkages between contribution and outcome across the thousands of system participants are not as clear. We present results from a tablet-PC-based game implemented in the field that shares much in common with the works of D'Exelle et al. (2012), Janssen et al. (2011), and Cardenas et al. (2013) but is tailored to the reality of the IBIS and thus differs in several key respects.

First, our game does not include the public-goods game of the Janssen and Cardenas groups. In the IBIS, farmers do pay water charges called abiana on a seasonal basis (Ghumman et al. 2011). Charged on a per-acre basis and varying by crop, these charges are collected by FOs, which retain a 50\% share and pass the rest on to provincial revenue departments (PIDA 2014). The link back to maintenance of higher order canals and distributaries is weak and not obvious to the contributing farmers, nor does the share retained locally contribute to a change in the availability of water made by the PID. Although farmers in some watercourses may invest in local infrastructure maintenance with benefits shared with other members of the watercourse, this link between contribution and function highlighted by the Janssen and Cardenas games, and more broadly for self-governing irrigation systems by Ostrom (1992), is much weaker in the massive IBIS and is not our focus. In our game, we incorporate a "protest" action (see Methods and Appendix 1) that allows players to reduce the water allocation of upstream players, acting in some ways as a punishment, and in others as an investment, but importantly providing a "second-level public good" (Chaudhuri 2011:68) to other downstream players. However, this is the extent to which our study approaches a public-goods game. The protest option is not something that currently has a clear, formal, and functional analog in water management systems in Pakistan. Rather, it represents a possible mechanism through which disputes and inequity could be resolved within the context of participatory water governance in the deeply hierarchical context of Pakistan, i.e., some investment of effort or resource by a downstream farmer leading to a shift in the allocated off-take to a farmer upstream. 
Second, although the experiments highlighted previously focus on the time taken for water capture by participants, our experiment treats water received in each round as a fixed quantity. Although the IBIS does operate on a time-based fixed-turn system, called warabandi, of 7- to 10-day cycles, the usage of time within these cycles is not of primary interest to us. The length of warabandi turns is calculated by a simple area-based formula, and though timing issues, unaccounted losses, and power dynamics lead to trading and significant deviations from this schedule (see, e.g., Bandaragoda 1998), these deviations do not vary much within a season. Rather than the issue of longer or shorter turns in a given week, we are interested in longer term shifts in allocation, obtained by lobbying officials to change official allocation or by illegal physical manipulation of the gravity-fed system to increase flow to one's property, thus reducing availability downstream. We thus treat a round of our game as a season, rather than a warabandi turn, and frame water off-take during the round as the cumulative water obtained over a season, with more water taken during a season leaving less water available downstream.

Finally, a key object of study in both the D'Exelle et al. (2012) and Janssen et al. (2011) cases is the role of communication in improving cooperative outcomes, a concept that is both well studied and well reviewed in the literature (e.g., Crawford 1998, Andersson and Wengström 2012). We focus instead on information feedback on water supply and abstraction, with communication among players restricted regarding game decisions and the protest mechanism described subsequently acting as the sole means of direct interaction between players. This design allows us to isolate the effects in the game that might be expected from investment in flow monitoring and reporting instruments, separate from communication effects that might be expected from improved deliberative processes in participatory water management. The latter are important effects, worth examining in Pakistan's strong rural hierarchies, but fall outside of the scope of the current study.

\section{METHODS}

The study area is located in the Hakra command area, between latitude $29^{\circ} 3^{\prime} 35^{\prime \prime} \mathrm{N}$ to $29^{\circ} 56^{\prime} 3^{\prime \prime} \mathrm{N}$ and longitude $72^{\circ} 14^{\prime} 35^{\prime \prime} \mathrm{E}$ to $73^{\circ} 26^{\prime} 17^{\prime \prime} \mathrm{E}$ (Fig. 1). The gross command area of Hakra Canal is 1.29 million acres $\left(5220 \mathrm{~km}^{2}\right)$, with a culturable command area of 1.04 million acres $\left(4200 \mathrm{~km}^{2}\right)$. The climate is hot and is characterized by large seasonal fluctuations in temperature and rainfall. June is the hottest month when temperature frequently exceeds $48.9^{\circ} \mathrm{C}$; in January, temperatures range from $0^{\circ} \mathrm{C}$ to $24.2^{\circ}$ C. The average annual rainfall in this area is $200 \mathrm{~mm} / \mathrm{yr}$ and falls mainly during the summer monsoon from June to September.

The water table in the project area ranges from $<1 \mathrm{~m}$ to $\sim 25 \mathrm{~m}$. The major crops of the study area include wheat, cotton, sugarcane, fodder, and rice. The crop yields are typically low in this area. Average yields in tonnes per hectare (irrigated crops) are as follows: rice, 1.6; cotton, 1.3; wheat, 1.9; and sugarcane, 30. The cropping intensity is $129 \%$ on an annual basis (Kharif $=55 \%$, Rabi $=74 \%$ ), where $100 \%$ indicates 1 crop per year across $100 \%$ of the area, so that 2 complete crops would sum to $200 \%$.

Hakra Branch Canal is part of the AWB Bahawalnager Canal Circle. It includes 3 canal divisions, namely Fordwah, Sadiqia, and Hakra. There are in total 69 functional FOs under this AWB, of which 17 are included in the Hakra division.
Fig. 1. Study area.

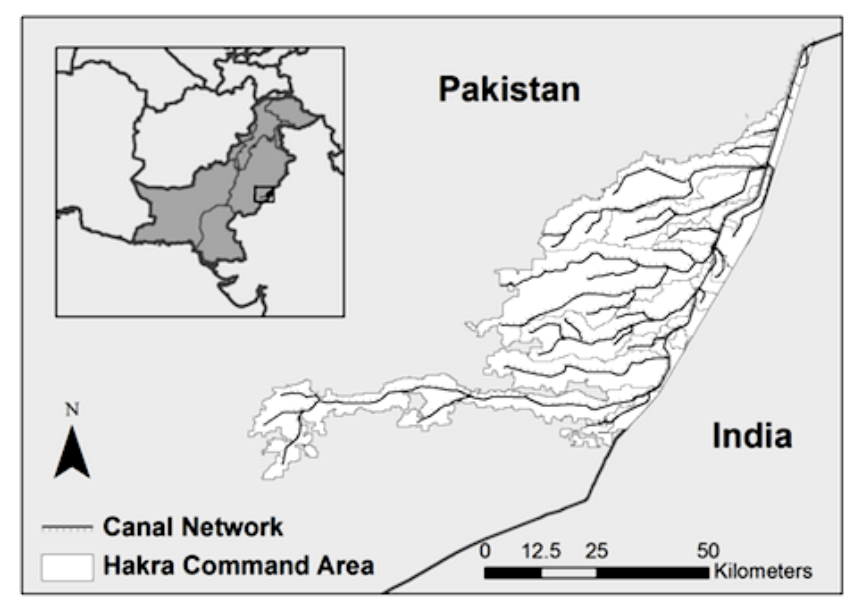

Game application and experiment

An English translation of the protocol administered to the participants is included in Appendix 1. In our game application, groups of 6 players are randomly assigned positions from 1 (upstream, head end) to 6 (downstream, tail end). In each round of the game, players receive water resources, which generate wealth; the wealth in turn can be spent on any or all of 3 actions: lobbying, protest, and maintenance. The processes governing water receipt and the nature of these 3 actions are described subsequently.

Each player's farm has a water "demand," i.e., the amount of water the player's farm requires to fully meet the water demands of the crops, above which there would be no further benefit to having more water; and a water "allocation," i.e., the amount of water the player is allocated to receive as it passes down the watercourse, which in this experiment was initialized to $80 \%$ of demand (Table 1), leaving potential incentive for players to bring more water into their farms. In each round of a game, players along the stream receive an amount of water equal to the lesser of (1) the water allocation or (2) the remaining water in the watercourse. Thus, if water in the watercourse is sufficient only for $k$ players, the $(k+1)$ th player will receive less than the full allocation, and players farther downstream will receive none; the allocation can thus be thought of as "water rights, pending availability." In sum, players have a distinct water "demand" and water "allocation," known and fixed, as well as actual water "receipt," resulting from the balance of inlet water to the watercourse and the allocations of players upstream.

Receipt of water generates "resources," i.e., leads to crop production and revenue. Players are told that they are able to accumulate these generated resources or spend them during their turn in any amount among three available actions: maintenance, lobbying, and protest (Fig. 2).

- Maintenance: Increases the resource generation on the player's plot per unit of water received by the player. In contrast to the public-goods games cited previously, in which investment increases the amount of water resources available 
Table 1. Game parameters.

\begin{tabular}{llc}
\hline \hline Parameter & Unit & Value \\
\hline Seepage Losses Between Players & $\%$ & 4 \\
Lobbying Cost & Resource Unit / Unit of Water Allocated & 15 \\
Maintenance Cost & Resource Unit / \% change in maintenance / ha & 0.6 \\
Protest Cost & Resource Unit / Unit of Water Allocated & 4 \\
Initial Maintenance Level & $\%$ Resource Units & 70 \\
Initial Capital & Water Units & 500 \\
Water Demand & Water Units & 400 \\
Initial Allocation & $\%$ & 320 \\
Maintenance decay & 2 \\
\hline
\end{tabular}

to the group, we use maintenance to refer only to what is occurring within the player's individual productive area and is not shared.

Fig. 2. Sample game screen shown to players in each round.

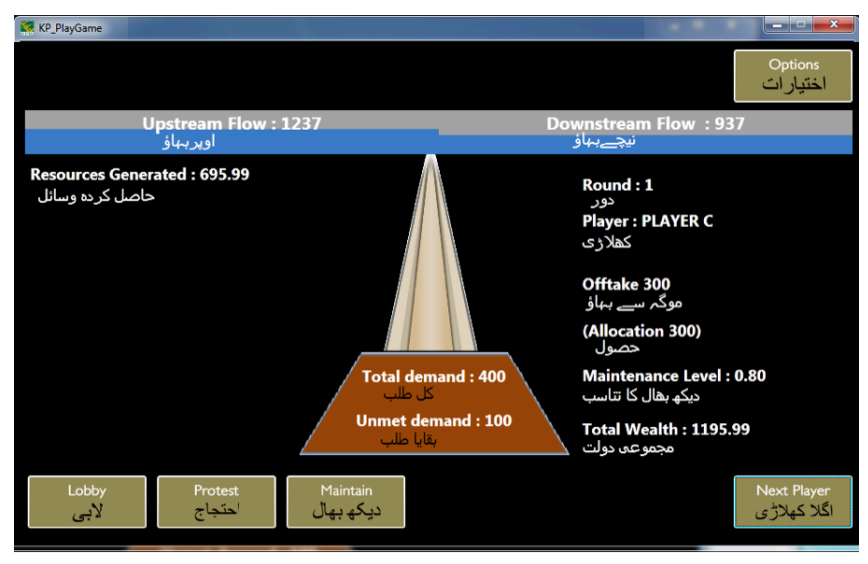

- Lobbying: Increases a player's water allocation. Lobbying represents the investment of resources and effort into increasing one's own water allocation, through any means, and is framed in the protocol to the players as not being an illegal activity. Lobbying does not explicitly reduce the allocation of other players, but if an increase in a player's allocation results in his receiving more water overall, this means that less water will continue downstream than would have otherwise. Under conditions of scarcity, lobbying can thus reduce the receipt of players downstream while not changing their allocations. Lobbying does not change the amount of water entering the watercourse, only the share of water passing along the watercourse that a player will retain; the amount of water entering the watercourse in each round is defined subsequently.

- Protest: Decreases the allocation of a target player. Protest represents a mechanism, perhaps realized through KP and FO meetings, through which users can invest their resources to challenge water allocations of other players, analogous to withholding contribution in the public-goods game. Though the protest of upstream players by downstream players would be expected to be most prevalent, any player can protest the allocation of any other player.
Players may undertake each of these three options as much or as little as they please, as long as they have the resources to pay for them. As is explained to the players in the protocol, these three options constitute a coherent set of responses to deficiencies in water supply. The protocol explains possible functions of these options as follows: (1) farmers whose allocations are insufficient can lobby to increase allocation; (2) farmers whose water receipt is less than their allocation can protest to increase the probability that sufficient water reaches their farm; and (3) farmers receiving adequate water, and thus not able to benefit further through lobby or protest, can improve productivity by investing in maintenance. In explaining these functions, the purpose is to illustrate functionality rather than suggest strategy. It is important to note that although these functions are suggested in the protocol, they in no way constrain the choices that players may make; thus, a player could lobby for an allocation well above his demand, for example, if he felt this buffer was of benefit or if he wished otherwise to affect downstream flow.

Players do not need to spend all of their resources and may simply keep them for accumulation. In the experimental protocol, players are instructed to try to maximize the wealth accumulated over the course of the game. Water capture is not directly a choice for each player: as in the real IBIS, players have a fixed allocation of water, in the case of our study, equal across players and initialized at $80 \%$ of full water demand, so that water receipt is equal to the lesser of the player's allocated water or the water remaining in the system. Generation of resources in each round is a logistic function of (1) water received, as a fraction of total water demanded, held fixed and constant across all players; and (2) maintenance level of the water infrastructure on their property (Fig. 3). In our experiment, the shape of this function was chosen only to capture the notion of decreasing marginal returns to spending on maintenance or increased water allocation. The functional form and parameters for this curve are included in Appendix 2. The shape was not communicated visually to participants, though the s-shape of the logistic curve was implied in the training protocol by noting that as maintenance approaches 1 and as off-take approaches demand, additional investment will yield weaker marginal returns. Maintenance refers only to the player's own property, and spending on maintenance has no effect on water resources received by other players.

We randomly selected 300 farmers from lists provided by FOs in the Hakra Branch command area, as well as a sample of 60 farmers listed as chairmen of their local KP, for a total of 506 player game sessions played with farmers from our initial random 
sample and 10 6-player game sessions played with our random sample of KP chairmen. Irrigation decisions are not commonly made by women in this region, and the household representatives making up our sample were all male. Each game session consisted of a 4-round practice session, followed by 2 6-round game treatments. In the first game treatment, i.e., "low information," players were not provided with any information about the decisions or off-take of other players in the game. Each player sat with an enumerator during their turn in a chair distanced from the other players (Fig. 4), rejoining the other players after the round was complete. Players were instructed not to discuss game actions while awaiting their turns but were allowed to freely discuss any other issues they desired; game play, including positions occupied along the in-game watercourse because players were called in order, was thus not anonymous.

Fig. 3. General form for resource generation response to increased maintenance $(\mathrm{X})$ and increased fraction of water demand met $(\mathrm{V})$.

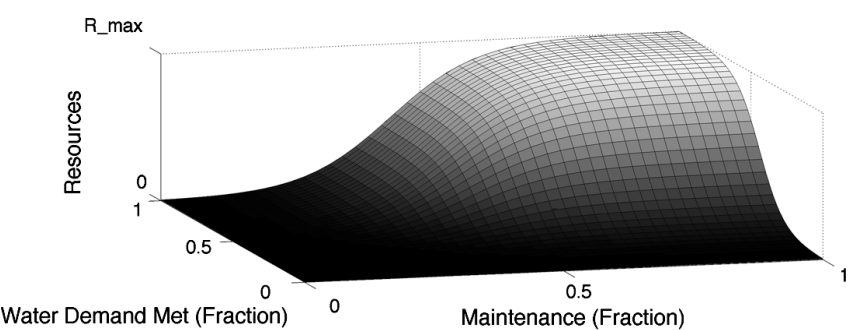

Fig. 4. Experimental setup. Farmers directed to welcome room upon arrival and escorted by enumerators to experiment room when six players were available. Enumerator (filled circle) sat separately with current player during each turn.

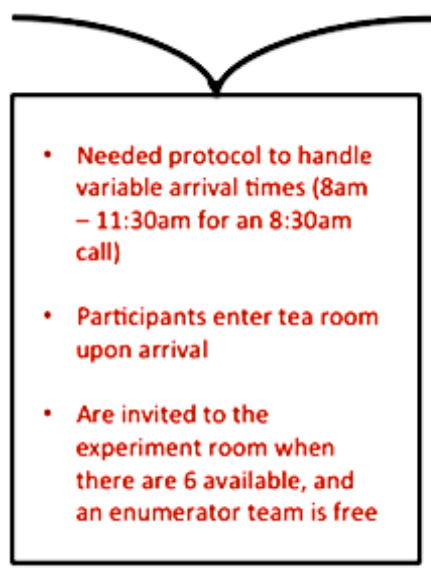

Welcome and Tea Room

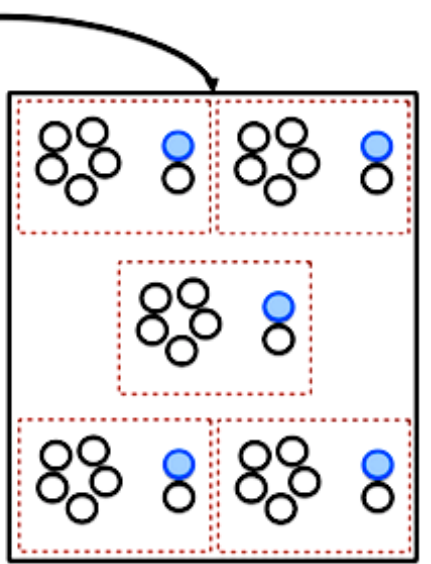

Experiment Room
In a second treatment, i.e., "high information," an information screen was shown to all players at the end of each round (Fig. 5) indicating the allocation, off-take, and demand of each player during the round; specific investments in lobbying, protesting, or maintenance remained private. Enumerators explicitly noted what each value meant and highlighted who had received what during the round. In an ideal experiment, these treatments would each have taken place with separate groups, i.e., 1 group, 1 treatment; however, because of the rather finite population of farmers and KP chairmen in the area, this design was selected as a compromise that represented a plausible change between treatments, i.e., installation of flow monitoring and information infrastructure. In all cases, this second treatment was played after the first treatment. Although this necessarily means that there is a learning effect confounded with the second treatment, we believe this to be a lesser issue than that posed by counterbalancing the design with half of the sample playing the information treatment first. That is, if the information treatment is played first, then lobbying behaviors revealed in the information treatment provide privileged knowledge as players return to a no-information condition in the second game. Under our chosen design, the impact of the learning effect can be examined in part via a round counter variable in regression analysis that counts continuously up from the first round through 12 for the end of the second treatment.

Fig. 5. Between-round information screen from information treatment.

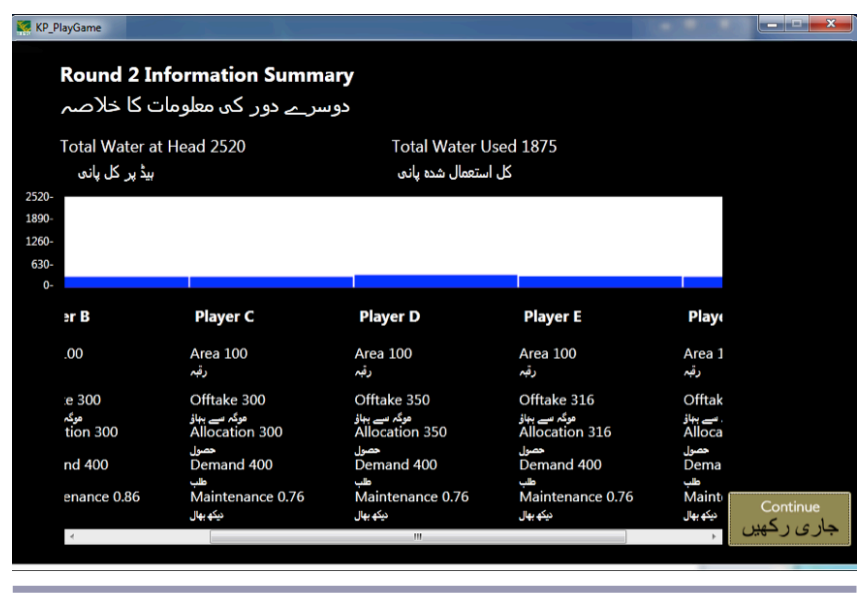

Round-wise water availability varied along the 6 rounds of each game but was identical in both low- and high-information treatments (Fig. 6). Farmers were not made aware in advance of water availability; they were only able to observe at the end of rounds in the information treatment how much water had been received. The total water entering the watercourse as a fraction of total water demanded by all farms, i.e., the delivery performance ratio, varied from nearly sufficient in rounds 1 and 2 , to scarcity conditions in rounds 3 and 4, during which water availability for the tail-end players (players 5 and 6) was compromised, and back to normal conditions in rounds 5 and 6 . Table 1 reports the game parameters including costs for lobbying and maintenance, which were calibrated to yield approximately equal returns under the initial conditions of the game. As stated previously, the functional form for resource generation was not explicitly revealed to the players, though they were instructed that returns would taper as maintenance and off-take grew (see Appendix 1 for protocol) and had the opportunity to practice before the game commenced. The costs for protests were held 
lower, such that downstream farmers not receiving water, and thus less able or not able to generate resources, would still have access to the protest mechanism. Evidence from other game experiments suggests that punishments need to have a lower cost and higher impact to be effective (Egas and Riedl 2008, Nikiforakis and Normann 2008), and the chosen cost in this experiment is meant to be low but not costless. A costless protest action could create the potential for a dominant strategy of protesting the complete allocation of all other players. Although it is not easy to evaluate the Nash equilibria, we believe, supported by our data, that our chosen cost level for protest is sufficient to avoid this dominant strategy.

Fig. 6. Round-wise delivery performance ratio.

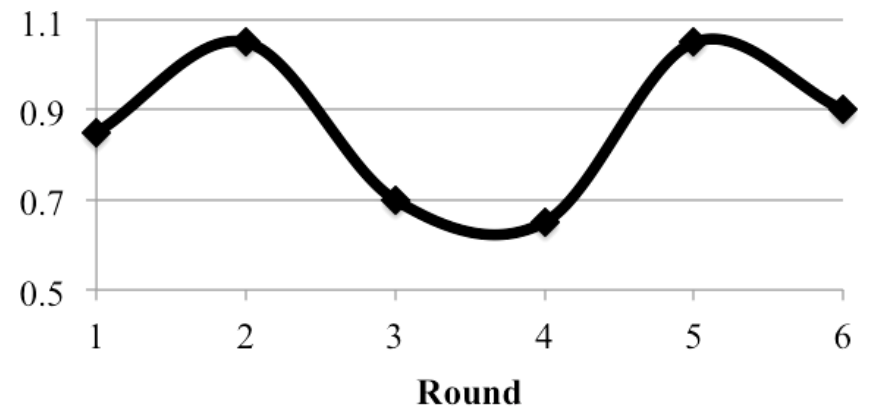

Participants were each given a box of local sweets to thank them for their time. Though a true competitive game with differing, fractionable payouts was deemed locally inappropriate, a compromise of offering an extra box of sweets to the player with the highest wealth score at the end of the session was made. Although a range of payouts based on score to each player would have been ideal to match real incentives for water capture, it was decided that an extra box of sweets, as a weak nudge toward competitive behavior, was preferred to no incentive at all. Games were programmed in the .NET framework for Windows 7 and played on an HP Slate 2 tablet PC. The compiled application is available by request from the authors.

\section{Equilibria and expected behavior}

It is not easy to evaluate the Nash equilibria for this game given the continuous distribution of choices, i.e., any level of investment in three different actions as well as retention of resources. Even simpler quantities such as the conditions under which the benefits of protest outweigh the transaction costs of making them depend too greatly on the actions of other players upstream to be clearly delineated. However, there are qualitative insights we can draw from the structure of the game and parameterization that provide some expectations about game behavior. A cooperative, equitable solution would see the players adjusting their allocation through the lobbying mechanism to raise their allocation or through protesting via themselves or others to reduce their allocation, such that they would receive, on average, knowing that allocation does not guarantee receipt, an equitable share of water resources. This is to say that even with incomplete accounting for losses, the tailend player (player 6) should receive some significant water resources, with players 1-5 all receiving adequate water. By contrast, the selfish (Nash) strategy of the player in all but the last round, in which no action by the player can influence outcomes, will depend on whether the player is receiving enough water. Players not receiving sufficient water have incentive to undertake maintenance to make use of available resources and to protest upstream allocations to bring more water downstream; in the absence of information, they cannot know who best to target with their protests. In contrast, players receiving enough water have incentive to secure their access to water by lobbying for additional resources, knowing that downstream players may protest, thereby reducing downstream resource generation and ability to protest. Thus, a long-run equilibrium with Nash strategies should yield a system in which upstream players have greater than adequate water receipt, whereas downstream players have no access to water nor any remaining resources through which to lodge protest. Depending on the variability of the inlet water, this could even lead to an equilibrium with only the headend player (player 1) receiving water.

We do not expect either such equilibria to emerge in the short period of play allowed by the field setting. However, we do wish to test whether there are system-level improvements of some kind in the distribution of water resources.

- H1: Access to flow information leads to a more equitable distribution of water receipt along the watercourse.

We are also interested in whether any such improvements occur because information provides a better basis for how to spend resources.

- H2: Access to flow information allows protests to be targeted more efficiently at those receiving excessive allocations.

Alternatively, we wish to see whether information simply changes the degree to which players make use of protest or lobby actions.

- H3: Access to information on downstream flow reduces player willingness to lobby or protest.

The kind of information provided in our information treatment is for outcomes, i.e., water received, rather than directly showing actions taken to change water receipt, i.e., lobbying or protest. This is in keeping with the nature of Pakistan's large statemanaged irrigation system, as opposed to the smaller, local public-good systems that are the subject of the studies by D'Exelle et al. (2012), Cardenas et al. (2013), and Janssen (2011). However, actions taken to raise water allocation, i.e., lobbying, are at least implicit in the eventual allocation, so that actions are not totally private. As such, where we find support for $\mathrm{H} 3$ we expect it to relate to both inequity aversion (Cox and Sadiraj 2012) in outcomes, i.e., observing what happens to other players, and also to some extent the avoidance of social disapproval, i.e., knowing that one's choices may be observed, as in studies by Rege and Telle (2004) or Croson and Shang (2008), in which information on the contribution, i.e., player action, is explicitly provided. As constructed, our treatments allow us to test the role of flow information in isolation from other modifiers on behavior, such as cheap talk and the opportunity for communication and coordination.

\section{RESULTS AND DISCUSSION}

\section{Game outcomes}

Sample game outputs from the two treatments are shown in Figures 7 and 8. Players invest in both maintenance and increased allocation throughout the game, leading to increased productivity 
Fig. 7. Sample game from low-information treatment. Quantities in left-hand panels indicated by axis titles.

Hakra, Day 6, Team 3, Game 159, Game Type 1

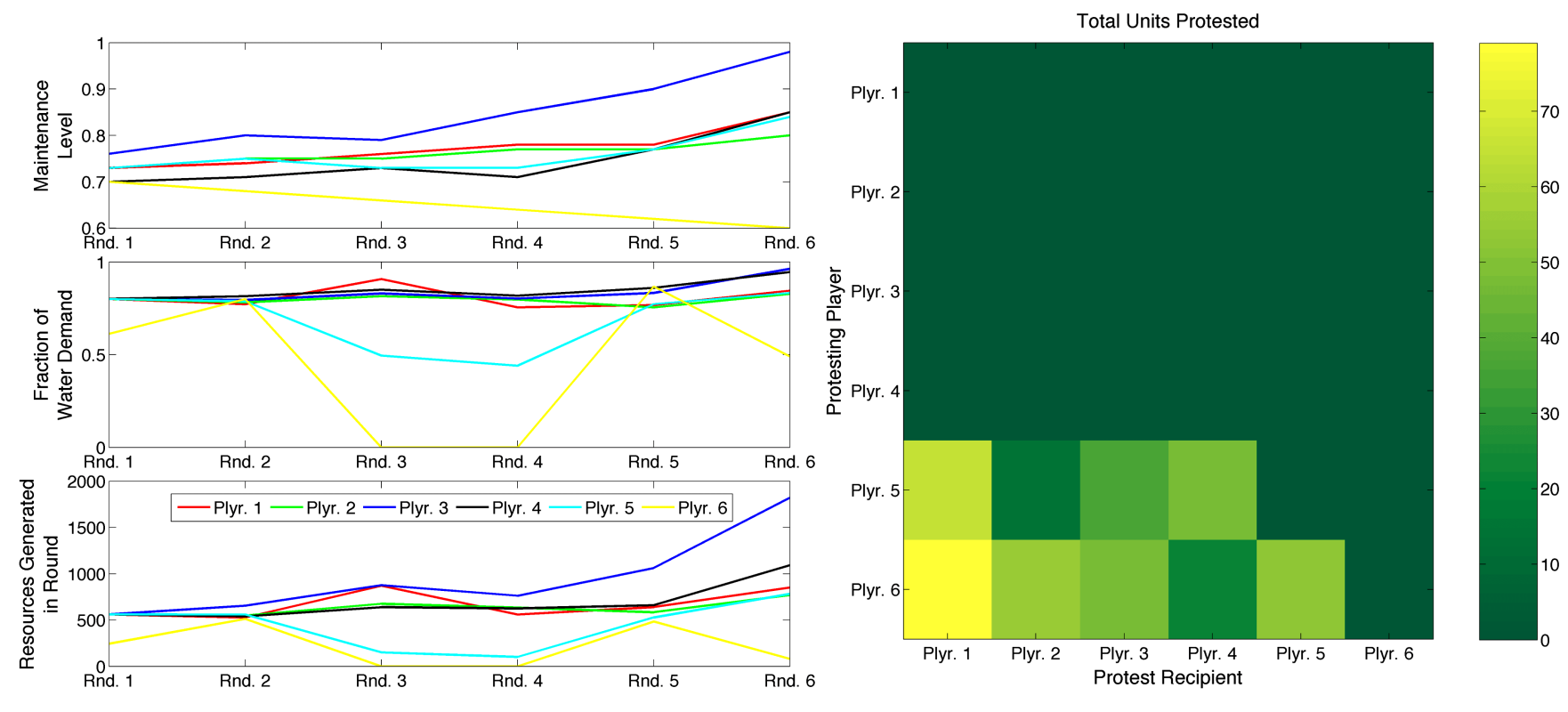

Fig. 8. Sample game from high-information treatment. Quantities in left-hand panels indicated by axis titles.

Hakra, Day 6, Team 3, Game 157, Game Type 2
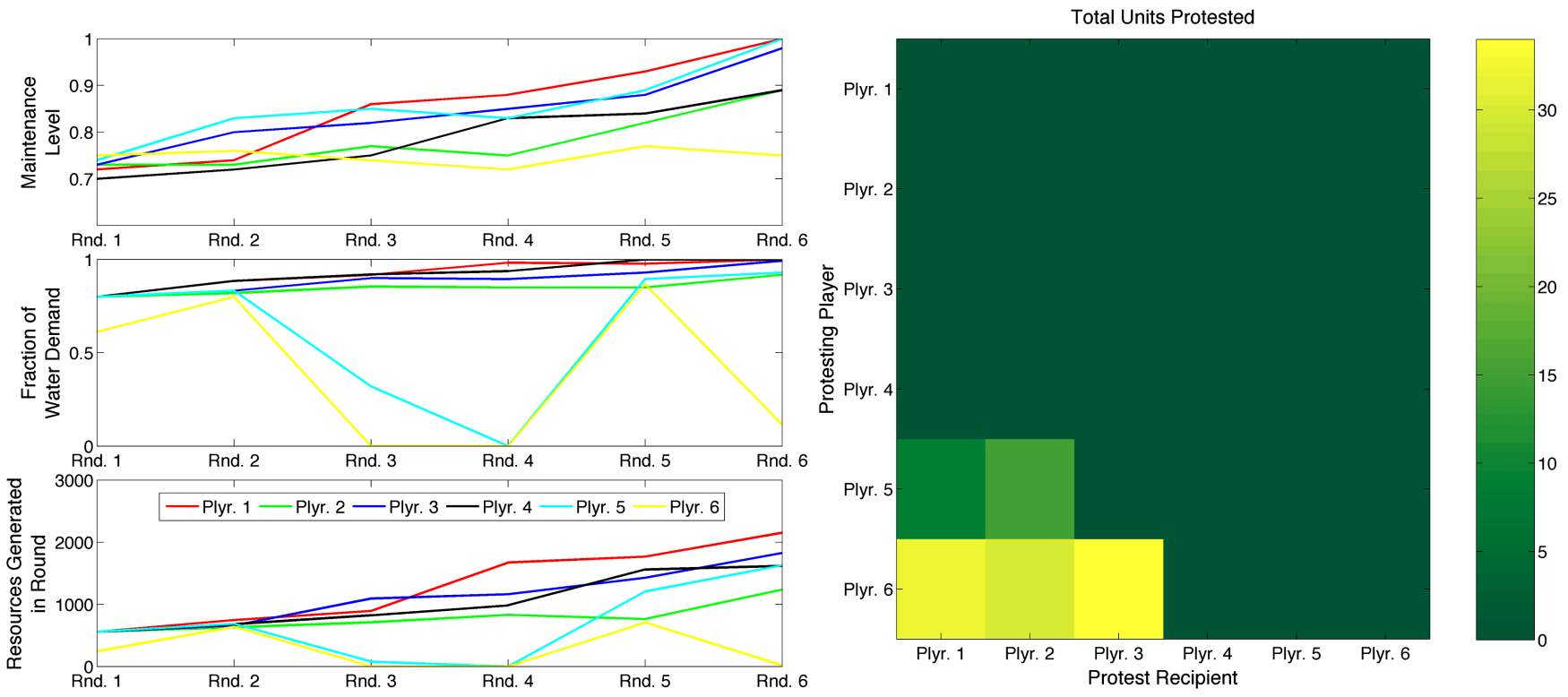

on average across the system by the end of the sixth round. A "heat map" of the sum of units of allocated water protested is shown at the right in each of Figures 7 and 8; row elements in these maps correspond to the player protesting, and column elements to the player whose allocation is being protested. Thus, elements below the diagonal are "upstream protests" from downstream players, and elements above the diagonal are "downstream protests" from upstream players. In this particular example, we see protesting only by players 5 and 6 , and once flow information is available to them, we see that their protests are 
Fig. 9. Game outcomes and actions: (A) water receipt, (B) Gini coefficient for water receipt, (C) lobby spending, (D) protest spending, and (E) protest receipt.

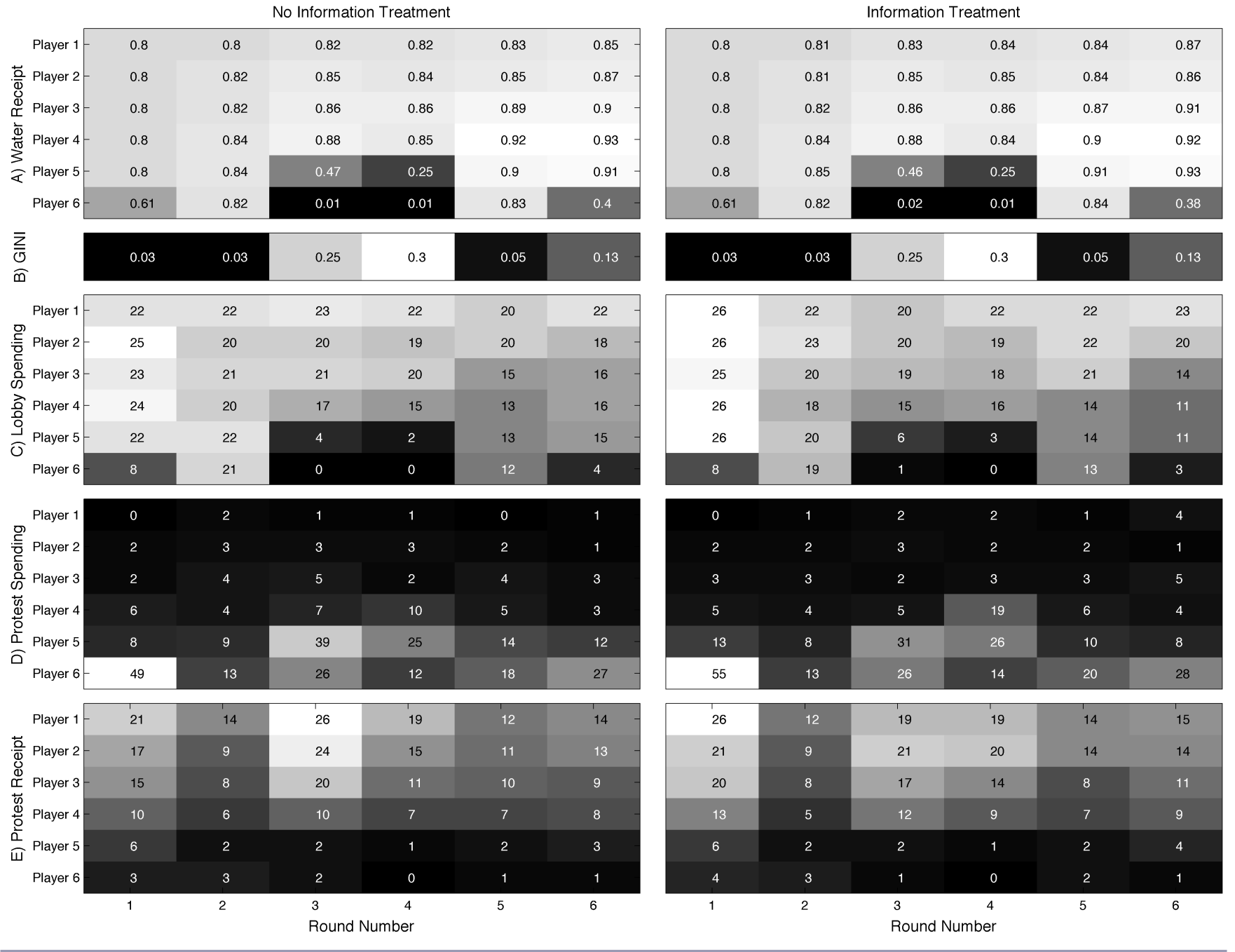

focused exclusively on the most upstream players. Other game outcomes show protesting efforts by those players higher upstream, including some downstream protesting, and we will look at these efforts in more detail shortly.

Shifting now to aggregated results over the whole study, we look first to the receipt of water resources by players across rounds and games (Fig. 9A-E). Water receipt shifts along the course of games, with water distribution much less equitable during rounds 3 and 4 , when water is scarce. Players 3 and 4 enjoy the greatest levels of water receipt, possibly reflecting an unfair targeting of headend players as sources of inequity. There are no real differences in equity across treatments, as measured by a Gini coefficient for water receipt (Fig. 9B); on the surface, we do not observe significant effects of information on game outcomes. We thus fail to find evidence to support H1, i.e., that information leads to any improvement in equity in the system. We also note that there is no reduction in lobbying by upstream players relative to the noinformation treatment, and thus we do not find support for the role of inequity aversion (H3) in player decisions (Cox and Sadiraj 2012) among upstream players. This is not necessarily surprising given the structure of the game, in which coordination was not enabled and there were no incentives provided to cooperate. However, we look again at $\mathrm{H} 3$ in the regression analyses outlined in Modeling in-game decision-making.

Of greater interest to us are the decisions made by players, specifically their engagement in protesting and lobbying activities. The overall game outcomes averaged by round and position in Figure 9 do not by themselves reveal much about participant decision making, though they do provide some indication that on average players understood the parameters of the game. Lobbying is the tool of choice for those upstream, whereas tail-end players rely more heavily on protesting as a means of increasing water receipt (Fig. 9C). One point of interest is the difference in drought response (rounds 3 and 4 ) by the 2 tail-end players (players 5 and 6). Player 5 increases protest efforts during the drought rounds, on average, but decreases as the drought abates in later rounds. 
By contrast, protest efforts by player 6 continue on after the drought has passed and even as water receipt by player 6 has increased; in particular, note that protest by player 6 increases on average in round 5 , when his water receipt is comparable to what the other players receive (Fig. 9D). It is not clear from the data we have collected whether this reflects different thinking or framing of scarcity by the 2 players, or whether it reflects similar thinking about different degrees of scarcity. The structure of the game as designed does not provide many points of entry into disaggregating these 2 effects, but the possible distinction between motives in protesting may be of interest in a future study.

We are able with this data to make a simple test of $\mathrm{H} 2$, i.e., whether protests are more effectively targeted with access to information. Figure 10 shows the distribution of protest spending as a function of the allocation of the targeted player in the previous round, both (1) without information and (2) with information. Two visible spikes in both distributions are at 320 , i.e., the starting allocation for all players ( $80 \%$ of demand), and at 400 , i.e., the total water demanded by each player's farm. Visually, the spike at 320 is reduced with information, whereas the spike at 400 is increased. Statistically, the mean of the distribution, i.e., the mean of water allocations receiving protest, increases from 330 to 334, a significant difference in a Mann-Whitney test at $\alpha=0.01$ and clear support for $\mathrm{H} 2$.

Fig. 10. Protest spending by targeted water allocation: (A) noinformation treatment and (B) information treatment.
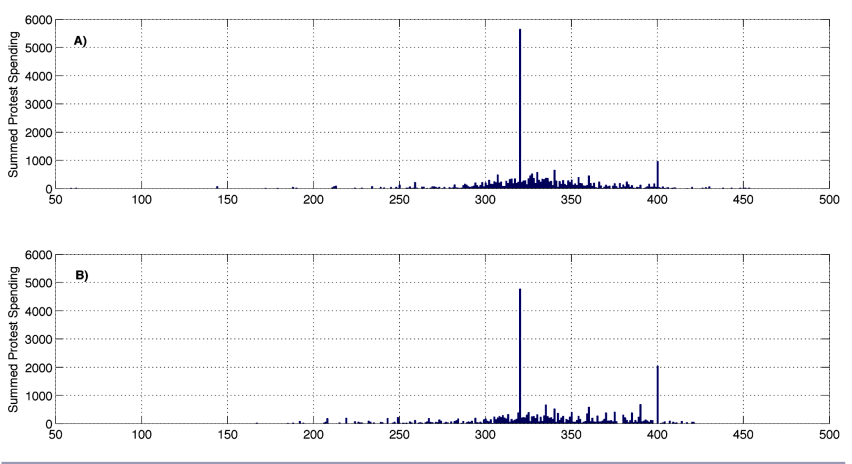

\section{Modeling in-game decision making}

Our data set additionally gives us a large body of decision data from the games from which to attempt to identify factors in decision making. We gain further insight into in-game decisions through multivariate regression for protesting and lobbying of the following form:

$$
P_{i}=\alpha_{i} X_{i}+\beta_{i} Y_{i}+\gamma_{i} Z_{i}+\varepsilon_{i}
$$

for the outcome of interest in round $i$, where $X_{i}$ is a vector of player control variables; $Y_{i}$ is a vector of in-game control variables; $Z_{i}$ is a vector of in-game decision variables; $\alpha, \beta$, and $\gamma$ are vectors of coefficients; and $\varepsilon$ is an error term. Analogously, overall regressions for each game, where the round number is a control variable. take the following form:

$$
P=\alpha X+\beta Y+\gamma Z+\varepsilon
$$

We have three decisions of interest, i.e., spending on protests, lobbying, and maintenance, as well as the outcome of protest receipt, revealing the extent to which protests are levied based on characteristics of the players or their in-game performance, with complete variable listings and regression outputs given in Tables 2-6. Descriptive statistics for these regression variables are given in Appendix 3. These estimates are for ordinary least-squares regression with Newey-West standard errors, which account for heteroskedasticity and autocorrelation in error terms, set to 1 period. All regression coefficients, except those for dummy variables, are for standardized (z-score) explanatory and response variables, so that they express the change in the response variable, in standard deviations, of a 1-standard-deviation change in the explanatory variable. This provides a coarse means, via their regression coefficients, of comparing the relative role of different variables in a single regression in explaining change in the response variable.

\section{Protesting}

Player controls do not appear to significantly explain protesting behavior. No player control coefficients in the overall regressions appear significant (Table 2), and those that appear in the playerby-player regressions are small and inconsistent (Table 3). Current spending on lobbying and maintenance are tied to protest spending in an expected way; greater spending on either lobbying or maintenance implies less spending on protest, with this effect, the trade-off among spending choices, being more pronounced for players farther downstream. Overall spending on protesting appears to be higher in later rounds in both games, and higher for players farther downstream. Protest spending appears to be negatively correlated with in-game wealth, with this effect much more strongly pronounced for players downstream. That is to say, protesting behavior appears greatest by those who are most affected, i.e., downstream players that are not generating wealth, validating the desired design criteria that access to protest not be costless but still remain available to those most in need of it. Comparing across games, spending on protesting is significantly lower in the information treatment, providing support for $\mathrm{H} 3$.

There are clear effects of water allocation and use on protest spending. The overall regressions suggest that having received more water in the previous round leads to higher protesting in both games, whereas higher allocations only lead to higher spending in the information treatment. A reduction in water allocation between rounds leads players to protest more in both games, whereas an increase in water use leads to increased protest in the no-information treatment only. However, these overall patterns mask important differences across players. First, water allocation and use are one and the same for players 1 through 3 because they always receive their full allocation. Allocated water is not a significant predictor for these 3 players in the noinformation treatment but has a small positive effect on protesting in the information treatment. For player 4, and for players 5 and 6 , there are larger contrasting effects. For player 4, both allocated water in the previous round and an increase in allocated water for the current round have moderate positive effects on protest spending; used water and increase in used water have stronger negative effects. The opposite for both allocated and used water is observed for players 5 and 6. It is not easy to disentangle these different effects, but they suggest that protesting has a different role for upstream players receiving close to their allocation than 
Table 2. Overall game regressions.

\begin{tabular}{|c|c|c|c|c|c|c|c|c|c|c|c|c|}
\hline \multirow[b]{2}{*}{ Variables } & \multicolumn{3}{|c|}{ Protest Spending } & \multicolumn{3}{|c|}{ Lobby Spending } & \multicolumn{3}{|c|}{ Maintenance Spending } & \multicolumn{3}{|c|}{ Protest Received } \\
\hline & $\begin{array}{l}\text { All } \\
\text { Games }\end{array}$ & No Info & Info & $\begin{array}{l}\text { All } \\
\text { Games }\end{array}$ & No Info & Info & $\begin{array}{l}\text { All } \\
\text { Games }\end{array}$ & No Info & Info & $\begin{array}{l}\text { All } \\
\text { Games }\end{array}$ & No Info & Info \\
\hline Protest & & & & $-0.167 * * *$ & $-0.169 * * *$ & $-0.163 * * *$ & $-0.140 * * *$ & $-0.143 * * *$ & $-0.136 * * *$ & $0.0445 * * *$ & $0.0544 * *$ & 0.0324 \\
\hline Lobby & $-0.207 * * *$ & $-0.207 * * *$ & $-0.205^{* * *}$ & & & & $-0.305 * * *$ & $-0.280 * * *$ & $-0.331 * * *$ & -0.000689 & 0.0226 & -0.0272 \\
\hline $\begin{array}{l}\text { Mainten- } \\
\text { ance }\end{array}$ & $-0.295 * * *$ & $-0.307 * * *$ & $-0.281 * * *$ & $-0.519 * * *$ & $-0.492 * * *$ & $-0.545^{* * *}$ & & & & -0.0125 & -0.00849 & -0.0179 \\
\hline Age & 0.000368 & 0.0109 & -0.00859 & -0.00437 & 0.00111 & -0.0105 & -0.00483 & -0.000350 & -0.0101 & $0.0291 * *$ & 0.0202 & $0.0373 * *$ \\
\hline $\begin{array}{l}\text { Education } \\
\text { Level }\end{array}$ & 0.0121 & 0.0106 & 0.0150 & 0.00113 & -0.0104 & 0.0118 & -0.0103 & -0.00520 & -0.0149 & 0.0173 & -0.0152 & $0.0515^{* * *}$ \\
\hline $\begin{array}{l}\text { KP } \\
\text { Chairman }\end{array}$ & -0.0194 & -0.0397 & 0.00208 & 0.0398 & 0.0437 & 0.0350 & -0.00839 & 0.0263 & $-0.0444 *$ & $-0.0527 * *$ & $\begin{array}{l}-0.0886- \\
* * *\end{array}$ & -0.0198 \\
\hline $\begin{array}{l}\text { Command } \\
\text { Area }\end{array}$ & 0.0226 & 0.0269 & 0.0202 & -0.00193 & 0.00378 & -0.00554 & $-0.0227 * * *$ & $-0.0274 * * *$ & $-0.0198 * * *$ & $0.0794 * *$ & 0.0985 & $0.0669 *$ \\
\hline $\begin{array}{l}\text { Property } \\
\text { Size }\end{array}$ & -0.0104 & 0.00156 & -0.0229 & 0.0142 & 0.0161 & 0.0123 & -0.000960 & 0.000472 & -0.00213 & $-0.0244 * * *$ & -0.0188 & $-0.0318 * *$ \\
\hline $\begin{array}{l}\text { Farm } \\
\text { Location }\end{array}$ & 0.00577 & -0.00742 & 0.0196 & 0.00466 & 0.00359 & 0.00553 & 0.00626 & 0.00371 & 0.00862 & 0.0126 & 0.00563 & 0.0212 \\
\hline Site & 0.00540 & -0.0200 & 0.0293 & 0.00461 & 0.00625 & 0.00466 & $0.0716^{* * *}$ & $0.0596 * * *$ & $0.0835^{* * *}$ & $-0.0798 * * *$ & $-0.0884 * *$ & $-0.0748 * *$ \\
\hline $\begin{array}{l}\text { Allocatio- } \\
n \_t-1\end{array}$ & $0.0400 * * *$ & 0.0145 & $0.0670^{* * *}$ & -0.00986 & -0.00768 & -0.0139 & $0.101 * * *$ & $0.107 * * *$ & $0.0931 * * *$ & $-0.0323 * *$ & $-0.0458 * *$ & -0.0220 \\
\hline Use_t-1 & $0.241 * * *$ & $0.265 * * *$ & $0.217 * * *$ & $0.570 * * *$ & $0.580 * * *$ & $0.558 * * *$ & $0.486 * * *$ & $0.482 * * *$ & $0.489 * * *$ & $0.0974 * * *$ & $0.0655 * * *$ & $0.129 * * *$ \\
\hline$\Delta$ Allocation & $-0.0518 * * *$ & $-0.0654 * * *$ & $-0.0375^{* *}$ & $-0.139 * * *$ & $-0.127 * * *$ & $-0.150 * * *$ & 0.00105 & -0.00188 & 0.00137 & $-0.115 * * *$ & $\begin{array}{l}-0.0998- \\
* * *\end{array}$ & $-0.128 * * *$ \\
\hline$\Delta$ Use & $0.0757 * * *$ & $0.0962 * *$ & 0.0551 & $0.533 * * *$ & $0.533 * * *$ & $0.533 * * *$ & $0.502 * * *$ & $0.495 * * *$ & $0.508 * * *$ & $0.0534 * * *$ & $0.0346^{*}$ & $0.0728 * * *$ \\
\hline $\begin{array}{l}\text { Protest } \\
\text { Return }\end{array}$ & 0.0326 & 0.0317 & 0.0326 & $-0.0203 * * *$ & -0.0142 & $-0.0328 * * *$ & 0.00343 & 0.00113 & 0.0116 & 0.00196 & 0.000687 & 0.00553 \\
\hline Wealth & $-0.380 * * *$ & $-0.399 * * *$ & $-0.355^{* * *}$ & $-0.735 * * *$ & $-0.714 * * *$ & $-0.758 * * *$ & $-0.794 * * *$ & $-0.771 * * *$ & $-0.819 * * *$ & $-0.0697 * * *$ & -0.0272 & $-0.108 * * *$ \\
\hline $\begin{array}{l}\text { Mainten- } \\
\text { ance } \\
\text { Level }\end{array}$ & $0.0399 *$ & $0.0587 * *$ & 0.0143 & $0.286^{* * *}$ & $0.276^{* * *}$ & $0.300 * * *$ & $0.554 * * *$ & $0.545^{* * *} *$ & $0.565^{* * *}$ & -0.0313 & -0.0410 & -0.0250 \\
\hline $\begin{array}{l}\text { Player } \\
\text { Number }\end{array}$ & $0.235^{* * *}$ & $0.259 * * *$ & $0.210 * * *$ & $-0.114^{* * *}$ & $-0.0951 * * *$ & $-0.133^{* * *}$ & 0.0145 & 0.0215 & 0.00666 & $-0.302 * * *$ & $-0.309 * * *$ & $-0.295^{* * *}$ \\
\hline $\begin{array}{l}\text { Round } \\
\text { Number }\end{array}$ & $0.264 * * *$ & $0.243 * * *$ & $0.286 * * *$ & $0.226^{* * *}$ & $0.204 * * *$ & $0.248 * * *$ & $0.0585^{* * *}$ & 0.0320 & $0.0856 * * *$ & $0.0648 *$ & -0.00373 & $0.133 * * *$ \\
\hline $\begin{array}{l}\text { Informat- } \\
\text { ion? }\end{array}$ & $-0.482 * * *$ & & & $-0.405 * * *$ & & & $-0.0752 *$ & & & $-0.115^{*}$ & & \\
\hline Constant & $0.239 * * *$ & $0.236 * * *$ & $-0.279 * * *$ & $0.191 * * *$ & $0.171 * * *$ & $-0.233 * * *$ & 0.00403 & -0.0199 & $-0.0950 * * *$ & $0.105 * * *$ & 0.0540 & -0.0807 \\
\hline $\begin{array}{l}\text { Observat- } \\
\text { ions }\end{array}$ & 6,510 & 3,288 & 3,222 & 6,510 & 3,288 & 3,222 & 6,510 & 3,288 & 3,222 & 6,510 & 3,288 & 3,222 \\
\hline
\end{tabular}

it does for those downstream who are not. It may be that downstream players whose allocations are relatively low, but who are receiving enough water to generate wealth, are protesting more; upstream players instead may be protesting "defensively" to protect their allocations. Our "return to protest" variable, calculated as the increase in water received per unit of protest spending in the prior turn, a proxy for the perceived worth of protesting, does not appear as significant overall in either game.

\section{Receiving protests}

Player characteristics explain variance in the receipt of protest differently between the 2 games. Notably, KP chairmen are less likely to be protested against in the no-information game, outside of the 2 drought rounds (rounds 3 and 4). However, this effect is not present in the information game. Older and more educated players receive greater protest in the information game, as do those from smaller farms and from larger watercourses, but this is not true for the no-information game. Players upstream receive more protests, unsurprisingly; more protests are received in later rounds in the information case, with no significant effect in the noinformation case. Because protest spending was found to be significantly lower in the information treatment, it is not surprising that, overall, protest receipt as well is lower in the information treatment.

Among in-game decision variables, the amount of water received is a significant direct predictor of protest receipt in the information case, but not in the no-information case. Although these results are not clear in the player-by-player regressions, they provide the most easily interpreted indication that players consume information to more effectively identify overuse of water. Possibly supporting this is that players with lower allocations, as distinct from water receipt, received more protest in the no-information case, but not once information was available. Looking for more detail in the player-by-player regressions (Table 4), the clearest effect on protest receipt is for player 4 . Higher water use in the prior round, and an increase in water use between rounds, has a strong effect on protest receipt across both games. 
Table 3. Player-by-player regressions: protest spending.

\begin{tabular}{|c|c|c|c|c|c|c|c|c|c|c|c|c|}
\hline \multirow[b]{2}{*}{ Variables } & \multicolumn{6}{|c|}{ No Info } & \multicolumn{6}{|c|}{ Info } \\
\hline & Player 1 & Player 2 & Player 3 & Player 4 & Player 5 & Player 6 & Player 1 & Player 2 & Player 3 & Player 4 & Player 5 & Player 6 \\
\hline Lobby & -0.0188 & $-0.0804 *$ & $-0.105^{* * *}$ & $-0.114 *$ & $-0.574 * * *$ & $-0.924 * * *$ & 0.00420 & $-0.0390 *$ & $-0.108 * *$ & $-0.288 * * *$ & $-0.657 * * *$ & $-0.784 * * *$ \\
\hline Maintenance & -0.0349 & $-0.131 * *$ & $-0.148 * * *$ & $-0.114^{*}$ & $-0.959 * * *$ & $-0.689 * * *$ & $-0.0601 *$ & $\begin{array}{c}-0.0703- \\
* * *\end{array}$ & $-0.197 * * *$ & $-0.270 * * *$ & $-0.645^{* * *}$ & $-0.452 * * *$ \\
\hline Age & -0.0221 & $-0.0493 * *$ & $0.0717^{*}$ & -0.0161 & -0.0142 & -0.0194 & -0.0236 & -0.0202 & 0.0395 & -0.0623 & -0.0358 & -0.0755 \\
\hline Education Level & $0.0307^{*}$ & 0.00824 & 0.0558 & 0.00920 & -0.0330 & -0.0468 & 0.0211 & 0.00317 & 0.0232 & 0.0105 & -0.0108 & 0.0494 \\
\hline $\begin{array}{l}\text { Khal Panchayat } \\
\text { Chairman }\end{array}$ & -0.0338 & -0.0490 & 0.0236 & $-0.170 * * *$ & -0.0328 & -0.00803 & -0.0489 & 0.0472 & 0.0318 & -0.0251 & -0.181 & 0.147 \\
\hline Command Area & -0.0195 & $-0.0629 * *$ & 0.0131 & 0.115 & 0.000281 & 0.0263 & -0.0303 & 0.00455 & 0.0186 & -0.0877 & -0.00891 & 0.0124 \\
\hline Property Size & -0.0203 & -0.00229 & -0.00766 & $0.116^{*}$ & 0.114 & -0.00296 & 0.0470 & $-0.0227^{*}$ & -0.0125 & -0.0395 & -0.00386 & -0.00617 \\
\hline Farm Location & $-0.0385^{*}$ & -0.000860 & 0.0447 & -0.00885 & 0.0221 & 0.00167 & 0.0501 & 0.0203 & 0.0386 & 0.00329 & $0.0976 * *$ & -0.0535 \\
\hline Site & $0.0598 *$ & -0.0771 & -0.0637 & $-0.185^{*}$ & -0.106 & 0.0517 & -0.0555 & 0.00869 & -0.0279 & 0.00156 & 0.0847 & $0.247 * *$ \\
\hline Allocation_t-1 & -0.00180 & 0.101 & -0.0198 & $0.351 * *$ & -0.0295 & $-0.364 * * *$ & $0.116^{* *}$ & $0.0562 * *$ & $0.0732 *$ & $0.591 * * *$ & $-0.229 * * *$ & $-0.295 * *$ \\
\hline Use_t-1 & & & & $-0.940 * *$ & $0.916^{* * *}$ & $0.668 * * *$ & & & & $-1.553 * * *$ & $0.610 * * *$ & $0.563 * * *$ \\
\hline$\Delta$ Allocation & -0.0164 & -0.0520 & $-0.0559 *$ & $0.195 * *$ & $-0.280 * * *$ & $-0.343 * * *$ & 0.0135 & -0.0129 & 0.00216 & $0.324 * * *$ & $-0.267 * * *$ & $-0.505 * * *$ \\
\hline$\Delta$ Use & & & & $-1.293 * * *$ & $0.661 * * *$ & $0.512 * * *$ & & & & $-2.047 * * *$ & $0.404 * * *$ & $0.369 * * *$ \\
\hline Protest Return & 1.075 & $-3.061 *$ & 1.327 & -0.101 & $0.0685^{* *}$ & 0.0241 & 0.164 & $-2.806^{* *}$ & -0.592 & $-2.264 * *$ & 0.0140 & $0.0699 * *$ \\
\hline Wealth & -0.0448 & $-0.193 * *$ & $-0.154 * * *$ & $-0.292 * * *$ & $-1.661 * * *$ & $-1.660 * * *$ & $-0.135^{*}$ & $-0.111 * * *$ & $-0.214 * * *$ & $-0.463 * * *$ & $-1.209 * * *$ & $-1.247 * * *$ \\
\hline Maintenance Level & 0.0107 & 0.0125 & -0.0171 & 0.00279 & $0.208 * *$ & -0.122 & -0.0258 & 0.00919 & 0.0887 & 0.0720 & -0.0350 & $-0.302 * * *$ \\
\hline Round Number & -0.0166 & 0.100 & $0.175^{*}$ & $0.351 *$ & $0.474 * *$ & 0.153 & $0.234^{*}$ & 0.0657 & $0.202 * *$ & $0.556 * * *$ & $0.564 * * *$ & 0.177 \\
\hline Constant & $-0.316^{* * *}$ & -0.295 & 0.134 & $0.860 * * *$ & $0.582^{* * *}$ & $-0.586^{*}$ & $-0.417 * * *$ & $-0.531 * * *$ & $-0.374 * * *$ & 0.113 & $-0.493 * * *$ & $-0.835^{* * *}$ \\
\hline Observations & 548 & 548 & 548 & 548 & 548 & 548 & 537 & 537 & 537 & 537 & 537 & 537 \\
\hline
\end{tabular}

\section{Lobbying}

Player controls do not appear to explain variation in lobbying; lobbying appears to increase in later rounds in both games and to be undertaken more by upstream players in both games (Table 2 ). As with the case of protesting, the availability of information reduces lobbying relative to the no-information treatment, further support for $\mathrm{H} 3$.

Overall, lobbying behavior is similar across both games, associated with those who are receiving higher amounts of water both in previous and current rounds. Across both games, lobbying is associated with reduced allocations from the prior round, suggesting that much of lobbying is a continuous battle to keep allocations high. Taken together with the observation that lobbying activities are also associated with lower in-game wealth, this provides evidence of the overall welfare losses associated with conflicts over allocation.

One additional insight gleaned from the player-by-player regressions (Table 5) is that, although water allocation appears insignificant in the overall regressions, it may be more accurate to say that prior water allocation is positively associated with lobbying for upstream players (players 1-3), but negatively associated with lobbying for downstream players (players 4-6). This likely reflects an understanding by downstream players that, barring availability of water resources downstream, increased allocations would have little effect.

\section{Maintenance}

Finally, we turn our attention to spending on maintenance (Tables $2,6)$. Spending on protest and lobbying are negatively associated with spending on maintenance; farmers from larger watercourse commands and those from the Fordwah site spend less on maintenance.

The effects of interest to us appear to be held in common across treatments in the maintenance case. Overall, investment in maintenance is higher among those receiving more water and those allocated more water, suggesting that, at least in some cases, those who have sufficient resources allocated and are receiving them undertake it. However, as with lobbying, these overall effects mask differences along the game watercourse. Both allocated water and an increase in allocated water have moderate positive effects on maintenance; these seem to decrease, become negative, or disappear downstream. The amount of water used in the prior round, which is distinct from water allocated only for players 4-6, and its change also have large positive associations with maintenance that appear to be smaller for players farther downstream.

\section{Speculation}

Our experiment as designed generated results that show relationships across spending on different actions; the underlying mechanisms for these relationships are not easily disaggregated using our data. For example, the negative associations across spending on protest, lobbying, and maintenance may simply reflect a basic constraint, i.e., points spent on one cannot be spent on the other, but it may be that there are more interesting substitutions occurring. It may be that higher investment in maintenance is tied to an abstention from protest or lobbying. In this game, maintenance applies only to the player's own property and not to the shared system, but perhaps the tendency to abstain from protesting or lobbying reflects an adherence to the Ostrom design principle for common pool resource (CPR) systems (no. 2 of 8), which suggests that functional CPR systems exhibit congruence between rules for appropriation and for provision (Ostrom 1990). Though it is beyond the scope of the current study, further analysis of the data and perhaps other targeted field studies ought to investigate what separates a "lobbier" or "protester" from a "maintainer." Certainly, most players engage in both of these strategies, but knowing whether a tendency toward one or the other could be explained through farm 
Table 4. Player-by-player regressions: protest receipt.

\begin{tabular}{|c|c|c|c|c|c|c|c|c|c|c|c|c|}
\hline \multirow[b]{2}{*}{ Variables } & \multicolumn{6}{|c|}{ No Info } & \multicolumn{6}{|c|}{ Info } \\
\hline & Player 1 & Player 2 & Player 3 & Player 4 & Player 5 & Player 6 & Player 1 & Player 2 & Player 3 & Player 4 & Player 5 & Player 6 \\
\hline Protest & -0.0888 & 0.131 & $0.153^{* *}$ & 0.200 & $0.0410^{*}$ & 0.0457 & 0.219 & 0.0521 & $0.211^{* *}$ & $0.101 *$ & 0.0212 & 0.0220 \\
\hline Lobby & 0.0258 & 0.0666 & 0.0248 & -0.0241 & 0.000663 & -0.00103 & $-0.160 * * *$ & -0.0468 & 0.00799 & -0.0217 & 0.0176 & 0.0371 \\
\hline Maintenance & -0.0755 & 0.0430 & -0.0552 & -0.0448 & 0.0552 & $-0.140 * *$ & -0.0446 & -0.0709 & 0.0441 & $-0.145^{* *}$ & 0.0601 & 0.0240 \\
\hline Age & 0.0392 & 0.0405 & 0.00606 & -0.00889 & -0.00808 & 0.0135 & $0.118^{* *}$ & 0.000276 & 0.00989 & 0.0652 & 0.00891 & 0.00692 \\
\hline Education Level & -0.0299 & -0.0106 & -0.0795 & 0.0210 & -0.0165 & -0.0288 & 0.0655 & $0.127^{* *}$ & -0.0452 & $0.120^{* * *}$ & 0.00520 & $-0.0205^{*}$ \\
\hline $\begin{array}{l}\text { Khal Panchayat } \\
\text { Chairman }\end{array}$ & $-0.194 * *$ & -0.0397 & -0.0342 & $-0.136^{*}$ & $-0.0696^{* *}$ & -0.00826 & 0.0737 & -0.0851 & -0.0835 & -0.0412 & 0.0436 & -0.0245 \\
\hline Command Area & 0.0103 & -0.0107 & 0.0860 & $-0.234 * *$ & 0.0207 & $0.376^{* *}$ & $-0.210 * *$ & -0.0856 & 0.00620 & -0.0439 & $0.00900 *$ & $0.301 * * *$ \\
\hline Property Size & -0.0395 & -0.000593 & -0.00935 & $-0.0832 *$ & 0.0411 & $-0.0549^{*}$ & 0.0295 & $-0.0890^{*}$ & -0.0352 & 0.0179 & 0.0247 & $-0.0464 * * *$ \\
\hline Farm Location & -0.00412 & -0.0116 & -0.0181 & -0.0174 & 0.0131 & 0.00456 & 0.00877 & 0.0513 & -0.0478 & 0.0353 & 0.0281 & 0.00742 \\
\hline Site & -0.0724 & 0.0539 & -0.181 & -0.0267 & 0.0490 & $-0.188 * *$ & 0.0948 & -0.0444 & -0.0740 & -0.177 & 0.0360 & $-0.136 * * *$ \\
\hline Allocation_t -1 & 0.0387 & -0.0297 & 0.0179 & $-0.313 * * *$ & -0.0698 & -0.0144 & 0.0684 & $0.207 * *$ & 0.0184 & $-0.274 * * *$ & -0.0335 & -0.000251 \\
\hline Use_t -1 & & & & $0.825^{* * *}$ & -0.0172 & 0.0355 & & & & $1.117 * * *$ & 0.00746 & 0.0117 \\
\hline$\Delta$ Allocation & $-0.137 *$ & -0.0730 & -0.0547 & $-0.241 * *$ & -0.0127 & 0.0185 & $-0.176^{* * *}$ & -0.0518 & $-0.0900^{* *}$ & $-0.263^{* * *}$ & 0.0152 & -0.0263 \\
\hline$\Delta$ Use & & & & $0.780 * * *$ & -0.0256 & $0.0545^{*}$ & & & & $0.993 * * *$ & -0.0219 & 0.00658 \\
\hline Protest Return & -0.0249 & -0.126 & 2.063 & 0.224 & 0.00910 & -0.00158 & $-4.719 * *$ & -2.053 & -1.148 & -0.446 & 0.0187 & 0.00101 \\
\hline Wealth & $-0.187^{*}$ & -0.0296 & -0.0399 & -0.0709 & 0.104 & -0.0609 & $-0.260 * * *$ & $-0.301 * * *$ & -0.0674 & $-0.203^{* * *}$ & -0.0775 & -0.0880 \\
\hline $\begin{array}{l}\text { Maintenance Level, } \\
\text { current }\end{array}$ & 0.0426 & -0.0693 & -0.123 & -0.00137 & -0.0436 & 0.0630 & -0.0750 & -0.0129 & -0.124 & -0.0787 & 0.0203 & 0.00161 \\
\hline Round Number & -0.0555 & 0.0626 & 0.0688 & 0.138 & 0.0746 & -0.0965 & $0.444 * * *$ & $0.395^{* * *}$ & 0.210 & $0.326^{*}$ & 0.118 & -0.0559 \\
\hline Constant & $0.413^{*}$ & 0.340 & $0.557^{* *}$ & -0.181 & $-0.305^{* * *}$ & $-0.439 * * *$ & -0.238 & 0.0119 & 0.0188 & $-0.586^{* * *}$ & $-0.532 * * *$ & $-0.346 * * *$ \\
\hline Observations & 548 & 548 & 548 & 548 & 548 & 548 & 537 & 537 & 537 & 537 & 537 & 537 \\
\hline
\end{tabular}

characteristics would be of significant value in devising institutions for irrigation governance.

Like protesting and lobbying, spending on maintenance was also reduced in the information treatment. Though it is not clear why information would reduce spending on maintenance, it may serve as a partial explanation as to why wealth levels are not higher in the information treatment even as spending on lobbying and protest, i.e., the welfare losses, appear to be reduced; any potential gains are offset by a reduction in maintenance. Whether this reflects a reticence to be observed taking any action when information is shared, or whether this is simply an effect of learning or fatigue cannot be resolved from our data but would be an important design consideration for future study. Experiments that focus more directly on revealing what actions players are more and less willing to be observed undertaking may prove very interesting.

Having noted areas of focus for future studies, it is possible to speculate to some extent on the implications of the data we do have from the current study. We found support for our hypothesis $\mathrm{H} 3$, i.e., that information affected the use of lobby and protest mechanisms, but did not observe that upstream players in particular reduced their lobbying. Thus, this supports the idea of an overall effect of social disapproval, i.e., use of different actions reduced overall when observed by others, rather than inequity aversion. Because our information treatment always came after the no-information treatment, this may also reflect fatigue or a learning effect, though this result is robust to controls for the round.

We found support for $\mathrm{H} 2$, i.e., that protests were targeted more effectively, but not for $\mathrm{H} 1$; we did not observe any of the changes in behavior tested under $\mathrm{H} 2$ and $\mathrm{H} 3$ to have led to system-level changes in equity. It is possible that this might change over a longer period of game play, under different conditions of resource availability, or under different incentives given for game participation. We employed only one particular parameterization of the irrigation game and can only say that information was insufficient to improve conditions under this particular parameterization. If the result that information alone, combined with some mechanism for punishment, is not sufficient to give equity improvements holds under some relevant range of irrigation conditions, then this underscores the importance of finding ways forward for irrigation reform in Pakistan. Our experimental design creates a world in which punishment is private and neither side has the opportunity to explain his position, a world that is perhaps not too far from watercourses where strong hierarchies discourage open exchange. The literature on games is very clear that collective action improves with the opportunity to coordinate and cooperate, and equity improvements in the IBIS may rest largely on how successfully such opportunities can be provided by the KPs.

\section{CONCLUSIONS AND RECOMMENDATIONS}

Before discussing the implications of these results, it is important to emphasize the limitations of the experiment and the game context. First, as has been highlighted already, we drew on a relatively small sample because of limits of time and population, reflecting the challenges of a game context in which six participants are necessary to produce one game session.

Second, the nature of the field setup limits the length of games that can be played. In the experimental setup of Janssen et al. (2011), the networked computers and simultaneous play of timed rounds allowed for 20 rounds of play in a fairly short time. In our setup, with players participating serially, a game session of 2 6- 
Table 5. Player-by-player regressions: lobby spending.

\begin{tabular}{|c|c|c|c|c|c|c|c|c|c|c|c|c|}
\hline \multirow[b]{2}{*}{ Variables } & \multicolumn{6}{|c|}{ No Info } & \multicolumn{6}{|c|}{ Info } \\
\hline & Player 1 & Player 2 & Player 3 & Player 4 & Player 5 & Player 6 & Player 1 & Player 2 & Player 3 & Player 4 & Player 5 & Player 6 \\
\hline Protest & -0.133 & $-0.181 * * *$ & $-0.192 * * *$ & $-0.164 *$ & $-0.175^{* * *}$ & $-0.129 * * *$ & 0.0157 & -0.201 & $-0.167 * * *$ & $-0.241 * * *$ & $-0.183 * * *$ & $-0.101 * * *$ \\
\hline Maintenance & $-0.654 * * *$ & $-0.511 * * *$ & $-0.469 * * *$ & $-0.459 * * *$ & $-0.514 * * *$ & $-0.487 * * *$ & $-0.687 * * *$ & $-0.664 * * *$ & $-0.549 * * *$ & $-0.459 * * *$ & $-0.521 * * *$ & $-0.463 * * *$ \\
\hline Age & 0.0655 & 0.0621 & -0.0321 & 0.0117 & 0.00541 & -0.00690 & -0.0260 & 0.0132 & 0.0127 & 0.0128 & $-0.0676^{* *}$ & -0.000845 \\
\hline Education Level & 0.0250 & -0.0239 & 0.0192 & 0.0275 & -0.0400 & -0.0213 & $0.0870 * *$ & 0.0154 & 0.00782 & 0.0142 & -0.0432 & -0.00808 \\
\hline $\begin{array}{l}\text { Khal Panchayat } \\
\text { Chairman }\end{array}$ & 0.109 & 0.113 & 0.116 & -0.0419 & 0.00931 & 0.0260 & 0.109 & -0.00661 & 0.105 & 0.0249 & -0.0787 & 0.0120 \\
\hline Command Area & -0.0125 & 0.0146 & $0.128 * *$ & 0.140 & -0.0128 & $-0.0355^{* * *}$ & -0.0811 & 0.0178 & 0.0791 & 0.129 & $-0.0137^{*}$ & -0.0212 \\
\hline Property Size & -0.0531 & 0.0339 & $0.0686^{* *}$ & 0.0513 & 0.0280 & 0.00562 & -0.0134 & 0.0403 & 0.0124 & 0.0858 & 0.000421 & 0.00867 \\
\hline Farm Location & -0.0154 & 0.0110 & -0.00504 & 0.0289 & 0.0165 & 0.0117 & -0.0442 & 0.0328 & $0.0621 *$ & -0.00345 & 0.0333 & 0.00244 \\
\hline Site & 0.0599 & 0.0150 & -0.0494 & -0.0466 & -0.0658 & -0.00430 & 0.125 & 0.00480 & -0.0333 & -0.0807 & 0.0686 & -0.00120 \\
\hline Allocation_t-1 & $0.417 * * *$ & $0.205 * * *$ & $0.155^{* *}$ & $-0.372 * * *$ & -0.0656 & $-0.104 * *$ & $0.356 * * *$ & $0.328 * * *$ & $0.198 * * *$ & $-0.384 * * *$ & $-0.138 * * *$ & $-0.0759 *$ \\
\hline Use_t-1 & & & & $1.479 * * *$ & $0.720 * * *$ & $0.504 * * *$ & & & & $1.404 * * *$ & $0.621 * * *$ & $0.461 * * *$ \\
\hline$\Delta$ Allocation & $0.0704 *$ & -0.0288 & $-0.182 * * *$ & $-0.206^{* * *}$ & -0.0740 & $-0.158 * * *$ & -0.0559 & -0.0144 & -0.0654 & $-0.220 * * *$ & $-0.125^{* * *}$ & $-0.155^{* * *}$ \\
\hline$\Delta$ Use & & & & $0.926 * * *$ & $0.689 * * *$ & $0.512 * * *$ & & & & $0.731 * * *$ & $0.643 * * *$ & $0.484 * * *$ \\
\hline Protest Return & $-7.709 * * *$ & 1.064 & $5.469 * *$ & -1.410 & -0.0139 & -0.00622 & -0.811 & -1.349 & $2.711 * * *$ & 0.120 & $-0.0345 * * *$ & $-0.0249 *$ \\
\hline Wealth & $-1.056^{* * *}$ & $-0.734 * * *$ & $-0.818^{* * *}$ & $-0.824 * * *$ & $-1.109 * * *$ & $-1.555^{* * *}$ & $-1.072 * * *$ & $-0.919 * * *$ & $-0.815^{* * *}$ & $-0.849^{* * *}$ & $-1.130 * * *$ & $-1.466 * * *$ \\
\hline Maintenance Level & $0.378 * * *$ & $0.277 * * *$ & $0.240 * * *$ & $0.245 * * *$ & $0.233 * * *$ & 0.0187 & $0.363 * * *$ & $0.302 * * *$ & $0.267 * * *$ & $0.268 * * *$ & $0.201 * * *$ & 0.0234 \\
\hline Round Number & $0.646^{* * *}$ & $0.438 * * *$ & $0.623 * * *$ & $0.746 * * *$ & 0.151 & $-0.328 * * *$ & $0.848 * * *$ & $0.576^{* * *}$ & $0.608 * * *$ & $0.739 * * *$ & 0.149 & $-0.380 * * *$ \\
\hline Constant & $0.516 * * *$ & $0.761 * * *$ & $1.301 * * *$ & $0.379^{*}$ & -0.140 & $-1.307 * * *$ & $-0.362 *$ & -0.198 & -0.00882 & $-0.880 * * *$ & $-0.480 * * *$ & $-0.678 * * *$ \\
\hline Observations & 548 & 548 & 548 & 548 & 548 & 548 & 537 & 537 & 537 & 537 & 537 & 537 \\
\hline
\end{tabular}

round games plus training and practice consumed nearly 3 hours, making it difficult to play additional games. Given opportunity, additional treatments to test a "no-protest" option, and thus the overall effect of having this context-dependent punishment, or a cheap-talk scenario would have provided additional depth to our study and might have been possible under a faster-moving game environment. The time constraint also made it difficult to lengthen the games, allowing greater opportunity for behavioral patterns to emerge. In a well-cited lab study, Gächter et al. (2008) observed higher responses to punishment, i.e., greater contributions in a public-goods game, and stabilized cooperation, i.e., requiring less continued punishment, in longer form games, i.e., 50 rounds versus 10 rounds in 2 different treatments. Lab results do not always map well onto field results (e.g., Carpenter and Seki 2011), and the ability to validate such long-term punishment effects in a field setting would be highly desirable, highlighting the importance of further development in field experimental techniques. The pencil-and-paper experiments of Janssen et al. (2011) facilitated longer games in the field than ours, but at the expense of greater stylization of the game, highlighting an additional dimension of trade-off in designing effective field experiments.

Third, our game included a scarcity signal that had impacts only for the tail-end players in the game. Though this may better reflect the realities of watercourses in the IBIS, a stronger scarcity signal may have had the effect of inducing stronger behavioral signals and differences in game-level outcomes between our noinformation and information treatments. Carpenter (2007) observed improved contributions to a public good with larger group size, reminding us that the game-level outcomes we observed are a product not just of the actions available to the participants but also of the number of participants in the game. A pilot study, such as is planned within our research program, may provide additional empirical evidence of the role that flow information can play, given the number of downstream farmers impacted by water shortages in a real watercourse. Finally, and perhaps most importantly, it is important to note that the experimental game context may not capture the conditions of the real irrigation system that motivate strategic behavior nor engage the same thinking processes. This is very broadly true for framed behavioral experiments, in which researchers use stylized representations and small incentives in an attempt to force similar decisions to those made for more complex systems, with greater stakes and over longer timescales. Our game context included six players, with an attempt to represent processes relevant to a much larger system engaging many thousands of farmers. Players made decisions in a very short time to address water deficits that would require significant effort and risk in reality. Though our experience providing support during practice sessions and the summarized game results do not suggest that players had difficulty understanding the game, we must acknowledge a mismatch in the degree to which one player's actions might affect those of another in the game context relative to the IBIS.

With these caveats stated, there are several results worth highlighting. First, we observed that upstream players, whose water supply was unaffected by scarcity, did not change their behavior in response to information that downstream players were not receiving adequate water. It is not necessarily surprising that the equitable outcomes observed in the games of D'Exelle et al. (2012) or Cardenas et al. (2013) did not occur in the current study. In smallholder irrigation systems, infrastructure is a shared public good, providing an opportunity for tail-end players to punish through noncontribution to maintenance. Additionally, the stronger linkages among members of smallholder systems, and the plurality of issues over which they likely interact, provide greater opportunity for social pressure and community sanctioning. However, this mechanism does not exist in the same way in large public systems like the IBIS. We provided an 
Table 6. Player-by-player regressions: maintenance spending.

\begin{tabular}{|c|c|c|c|c|c|c|c|c|c|c|c|c|}
\hline \multirow[b]{2}{*}{ Variables } & \multicolumn{6}{|c|}{ No Info } & \multicolumn{6}{|c|}{ Info } \\
\hline & Player 1 & Player 2 & Player 3 & Player 4 & Player 5 & Player 6 & Player 1 & Player 2 & Player 3 & Player 4 & Player 5 & Player 6 \\
\hline Protest & $-0.116^{*}$ & $-0.166^{* * *}$ & $-0.162 * * *$ & $-0.0974^{*}$ & $-0.187^{* * *}$ & $\begin{array}{c}-0.0766- \\
* * *\end{array}$ & $-0.101^{* *}$ & $-0.198 * * *$ & $-0.195 * * *$ & $-0.168 * * *$ & $-0.160 * * *$ & $-0.0476 * * *$ \\
\hline Lobby & $-0.308^{* * *}$ & $-0.288 * * *$ & $-0.280 * * *$ & $-0.271 * * *$ & $-0.329 * * *$ & $-0.387 * * *$ & $-0.310 * * *$ & $-0.362 * * *$ & $-0.350 * * *$ & $-0.343^{* * *}$ & $-0.464 * * *$ & $-0.378 * * *$ \\
\hline Age & 0.0106 & 0.0278 & -0.00193 & 0.00167 & -0.0154 & -0.00211 & 0.00877 & -0.0265 & -0.00515 & 0.00933 & -0.0360 & 0.0100 \\
\hline Education Level & 0.000970 & -0.00218 & 0.00511 & 0.000250 & -0.00965 & -0.0162 & -0.00127 & -0.0173 & -0.0208 & -0.0120 & $-0.0534 * *$ & 0.00505 \\
\hline $\begin{array}{l}\text { Khal Panchayat } \\
\text { Chairman }\end{array}$ & 0.0494 & 0.0828 & -0.00660 & 0.00676 & 0.0173 & 0.0234 & -0.0298 & -0.0744 & -0.0726 & -0.0186 & -0.0905 & -0.0143 \\
\hline Command Area & -0.0607 & $-0.0761 * *$ & -0.0307 & -0.0407 & $-0.0219^{* *}$ & -0.00619 & $-0.0946^{* *}$ & -0.0176 & -0.0363 & 0.0165 & $-0.0147 *$ & $-0.0249 * * *$ \\
\hline Property Size & -0.0139 & 0.00375 & 0.00275 & -0.00882 & 0.0432 & -0.00881 & 0.0240 & 0.0286 & 0.00105 & 0.00248 & 0.0136 & -0.0102 \\
\hline Farm Location & -0.0250 & 0.0171 & -0.00239 & 0.0137 & $0.0500 * *$ & -0.0137 & 0.0154 & 0.0435 & 0.0385 & -0.0311 & 0.0201 & 0.00194 \\
\hline Site & $0.107^{*}$ & $0.0959 *$ & 0.0624 & 0.0289 & 0.0376 & -0.0118 & $0.128 * *$ & $0.127 * *$ & 0.0746 & 0.0939 & 0.0711 & 0.0241 \\
\hline Allocation_t-1 & $0.295 * * *$ & $0.316^{* * *}$ & $0.327 * * *$ & $-0.533 * * *$ & $0.121 * * *$ & 0.00965 & $0.287 * * *$ & $0.360 * * *$ & $0.294 * * *$ & $-0.314 * * *$ & 0.00998 & -0.00401 \\
\hline Use_t-1 & & & & $2.350 * * *$ & $0.701 * * *$ & $0.387 * * *$ & & & & $1.644 * * *$ & $0.712^{* * *}$ & $0.359 * * *$ \\
\hline$\Delta$ Allocation & $0.125 * * *$ & $0.109 * * *$ & $0.0617 * *$ & $-0.239 * * *$ & $-0.0741 * *$ & -0.0412 & $0.101 * * *$ & $0.157 * * *$ & $0.0886^{* * *}$ & $-0.206^{* * *}$ & $-0.0827 * *$ & -0.0652 \\
\hline$\Delta$ Use & & & & $1.800 * * *$ & $0.692 * * *$ & $0.428 * * *$ & & & & $1.495 * * *$ & $0.720 * * *$ & $0.414 * * *$ \\
\hline Protest Return & $-4.968 * *$ & 0.632 & 0.575 & 0.414 & $0.0383 * * *$ & -0.00119 & -0.966 & $-3.488 * * *$ & 1.306 & -0.614 & 0.0136 & -0.00392 \\
\hline Wealth & $-0.816^{* * *}$ & $-0.788 * * *$ & $-0.815^{* * *}$ & $-0.942 * * *$ & $-1.119^{* * *}$ & $-0.931 * * *$ & $-0.813 * * *$ & $-0.877 * * *$ & $-0.881 * * *$ & $-0.962 * * *$ & $-1.297 * * *$ & $-0.947 * * *$ \\
\hline Maintenance Level & $0.547 * * *$ & $0.518^{* * *}$ & $0.527 * * *$ & $0.632 * * *$ & $0.462 * * *$ & $0.437 * * *$ & $0.530 * * *$ & $0.538 * * *$ & $0.582 * * *$ & $0.549 * * *$ & $0.522 * * *$ & $0.430 * * *$ \\
\hline Round Number & 0.0763 & 0.116 & 0.179 & $0.342 * * *$ & 0.127 & $-0.209 * * *$ & 0.110 & $0.224 * * *$ & $0.217 * *$ & $0.486 * * *$ & $0.259^{* * *}$ & $-0.242 * * *$ \\
\hline Constant & -0.143 & $0.294 * *$ & $0.385 * *$ & $-0.341 *$ & -0.0499 & $-0.548 * * *$ & 0.0107 & $-0.250 * *$ & 0.116 & $-0.854 * * *$ & $-0.415^{* * *}$ & $-0.194 * *$ \\
\hline Observations & 548 & 548 & 548 & 548 & 548 & 548 & 537 & 537 & 537 & 537 & 537 & 537 \\
\hline
\end{tabular}

analogous punishment mechanism to other games by allowing protest by downstream players, acting to reduce upstream allocations, on which downstream players relied heavily. However, although access to information allowed these protests to be targeted more effectively by downstream players, it did little to change the behavior of upstream players, highlighting the key role that the public-good nature of small irrigation systems plays in shaping performance outcomes, which fails to emerge in this experiment. Players with high allocations were not more motivated to share water downstream, nor were players in the middle more motivated to punish those upstream for the effects they could now observe downstream. Following the observation of Egas and Reidl (2008) that altruistic punishment, i.e., sanctioning noncooperators without clear benefits to oneself, may be governed by cost-benefit considerations, this may simply suggest that those farmers receiving sufficient water do not have good reason to "rock the boat."

An important observation from this experiment is that although information on flows "works," i.e., those who consume more water resources are more effectively targeted when information is available, information alone does not appear to effectively address inefficiency and welfare loss in the system. Our experiment provided a credible but hypothetical response, i.e., protesting, to the existing issue of lobbying, which itself carried a cost of execution. The observation in our regression results that the levying of protests, the act of lobbying, and even maintenance were all associated with lower levels of in-game wealth, implying that those who spend more on any of these tools are not better off, illustrates that the value of conflict resolution mechanisms depends on the costs of employing them, and that minimizing welfare losses through improper allocation of water resources will depend in no small part on proper institutional developments for conflict resolution. Our protest mechanism captured only the concept of "If I spend some effort, I can reduce allocation to another farmer," without any heed to the kind of processes necessary to implement it. To some degree, existing arrangements in the KPs, i.e., water users associations, may provide a forum for irrigators to address conflicts in an analogous way, but this functioning of the KPs ought not be taken for granted. The reticence of players to protest their KP chairmen in the experiment, without clear evidence of their overconsumption, is a strong reminder of the hierarchy that remains even in these lowest level, participatory bodies. To the extent that a watercourse comprises a feudal landlord and his tenants, a participatory body formed for that watercourse could not be expected to address issues of underlying hierarchy from upstream to downstream. Inequities persist across Pakistan's irrigation system, and a message from this work is that technical interventions alone, i.e., installing and maintaining access to flow information, might not be sufficient to address them. In particular, empirical research identifying opportunities for cooperative behavior, and demonstrating where incentives exist for upstream farmers to factor those downstream into their decisions, will be important.

This experiment represents, as initially stated, a first step in our inquiry of how access to information can shape irrigation outcomes in large public irrigation schemes. Our next effort will be to implement a pilot study of flow monitoring and reporting in a distributary in the Hakra command and observe production and equity outcomes over the period of several seasons. We also have field experiments planned using games and choice experiments to examine behavior when farmers have access to clean and reliable groundwater, which will expand on and disentangle some of the observations of this first study related to water scarcity and to the dual role of protest as investment and punishment. Together, we hope these efforts will inform the value of investment in information for large irrigation systems such as in Pakistan's Indus Basin. 
Responses to this article can be read online at: http://www.ecologyandsociety.org/issues/responses. $\mathrm{php/7368}$

\section{Acknowledgments:}

This work was undertaken as part of the CGIAR Research Program on Policies, Institutions, and Markets (PIM) and facilitated by the Pakistan Strategy Support Program (PSSP) of the International Food Policy Research Institute (IFPRI) with funding support from PIM and USAID. We gratefully acknowledge the efforts of our enumeration team: Muhammad Mohsin Waqas, Ali Tahir, Asad Rehman Gill, Hafiz Muhammad Tahir, Hamid Saleh, Majid Ikram, Muhammad Hafeez, Muhammad Irshad Ahmed, Muhammad Shafeeque, and Zulqarnain Mushtaq.

\section{LITERATURE CITED}

Andersson, O., and E. Wengström. 2012. Credible communication and cooperation: experimental evidence from multi-stage games. Journal of Economic Behavior \& Organization 81:207-219. http://dx.doi.org/10.1016/j.jebo.2011.10.002

Asrar-UlHaq. 2010. Performance of farmers' organizations in Punjab, Pakistan: the challenges and way forward. Irrigation and Drainage 59:23-30. http://dx.doi.org/10.1002/ird.547

Azam, J.-P., and J.-D. Rinaudo. 2004. Encroached entitlements: corruption and appropriation of irrigation water in southern Punjab (Pakistan). Institut d'Économie Industrielle (IDEI) Working Papers, No. 252. IDEI, Toulouse, France.

Bandaragoda, D. J. 1998. Design and practice of water allocation rules: lessons from warabandi in Pakistan's Punjab. Research Report 17. International Irrigation Management Institute, Colombo, Sri Lanka.

Barker, R., and F. Molle. 2004. Evolution of irrigation in South and Southeast Asia. Comprehensive Assessment Research Report 5. Comprehensive Assessment Secretariat, Colombo, Sri Lanka.

Bengali, K. 2009. Water management under constraint: the need for a paradigm shift. Pages 45-63 in M. Kugelman and R. Hathaway, editors. Running on empty: Pakistan's water crisis. Woodrow Wilson International Center for Scholars, Washington, D.C., USA.

Briscoe, J., and U. Qamar. 2005. Pakistan's water economy: running $d r y$. World Bank, Washington, D.C., USA.

Cardenas, J.-C., M. Janssen, and F. Bousquet. 2013. Dynamics of rules and resources: three new field experiments on water, forests and fisheries. Pages 319-345 in J. A. List and M. K. Price, editors. Handbook on experimental economics and the environment. Edward Elgar, Cheltenham, UK. http://dx.doi.org/10.4337/978$\underline{1781009079.00020}$

Carpenter, J. P. 2007. Punishing free-riders: how group size affects mutual monitoring and the provision of public goods. Games and Economic Behavior 60(1):31-51. http://dx. doi.org/10.1016/j. geb.2006.08.011
Carpenter, J., and E. Seki. 2011. Do social preferences increase productivity? Field experimental evidence from fishermen in Toyama Bay. Economic Inquiry 49(2):612-630. http://dx.doi. org/10.1111/j.1465-7295.2009.00268.x

Chaudhuri, A. 2011. Sustaining cooperation in laboratory public goods experiments: a selective survey of the literature. Experimental Economics 14(1):47-83. http://dx.doi.org/10.1007/ s10683-010-9257-1

Cox, J. C., and V. Sadiraj. 2012. Direct tests of individual preferences for efficiency and equity. Economic Inquiry 50 (4):920-931. http://dx.doi.org/10.1111/j.1465-7295.2010.00336.x

Crawford, V. 1998. A survey of experiments on communication via cheap talk. Journal of Economic Theory 78(2):286-298. http:// dx.doi.org/10.1006/jeth.1997.2359

Croson, R., and J. Shang. 2008. The impact of downward social information on contribution decisions. Experimental Economics 11(3):221-233. http://dx.doi.org/10.1007/s10683-007-9191-z

D'Exelle, B., E. Lecoutere, and B. Van Campenhout. 2012. Equity-efficiency trade-offs in irrigation water sharing: evidence from a field lab in rural Tanzania. World Development 40 (12):2537-2551. http://dx.doi.org/10.1016/j.worlddev.2012.05.026

Egas, M., and A. Riedl. 2008. The economics of altruistic punishment and the maintenance of cooperation. Proceedings of the Royal Society B 275:871-878. http://dx.doi.org/10.1098/ rspb.2007.1558

Gächter, S., E. Renner, and M. Sefton. 2008. The long-run benefits of punishment. Science 322:1510. http://dx.doi.org/10.1126/ science. 1164744

Ghumman, A. R., R. A. Khan, H. N. Hashmi, M. A. Kamal, and I. T. Khan. 2011. Performance assessment of canal irrigation in Pakistan. African Journal of Agricultural Research 6 (12):2692-2698.

Janssen, M. A., J. M. Anderies, and S. R. Joshi. 2011. Coordination and cooperation in asymmetric commons dilemmas. Experimental Economics 14(4):547-566. http://dx.doi. org/10.1007/s10683-011-9281-9

Kahlown, M. A., and W. D. Kemper. 2005. Reducing water losses from channels using linings: costs and benefits in Pakistan. Agricultural Water Management 74(1):57-76. http://dx.doi. org/10.1016/j.agwat.2004.09.016

Khan, F. 2009. Water, governance, and corruption in Pakistan. Pages 82-104 in M. Kugelman and R. Hathaway, editors. Running on empty: Pakistan's water crisis. Woodrow Wilson International Center for Scholars, Washington, D.C., USA.

Latif, M., and J. A. Tariq. 2009. Performance assessment of irrigation management transfer from government-managed to farmer-managed irrigation system: a case study. Irrigation and Drainage 58:275-286. http://dx.doi.org/10.1002/ird.424

Meinzen-Dick, R., K. V. Raju, and A. Gulati. 2002. What affects organization and collective action for managing resources? Evidence from canal irrigation systems in India. World Development 30(4):649-666. http://dx.doi.org/10.1016/S0305-750X (01)00130-9 
Memon, N. A. 2006. Participatory irrigation management and institutionalizing irrigation service in Sindh. Pages 71-84 in Proceedings of the INPIM's Ninth International Seminar on Participatory Irrigation Management (Lahore, Pakistan, 4-8 December 2006). International Network on Participatory Irrigation Management, Islamabad, Pakistan.

Mukherji, A., B. Fuleki, T. Shah, D. Suhardiman, M. Giordano, and P. Weligamage. 2009. Irrigation reform in Asia: a review of 108 cases of irrigation management transfer. International Water Management Institute, Colombo, Sri Lanka. [online] URL: http://waterknowledgehub.iwmi.org/PDF/Irrigation_Reform_in_Asia. pdf

Nikiforakis, N., and H.-T. Normann. 2008. A comparative statics analysis of punishment in public-good experiments. Experimental Economics 11:358-369. http://dx.doi.org/10.1007/s10683-007-9171-3

Ostrom, E. 1990. Governing the commons: the evolution of institutions for collective action. Cambridge University Press, Cambridge, UK. http://dx.doi.org/10.1017/CBO9780511807763

Ostrom, E. 1992. Crafting institutions for self-governing irrigation systems. Institute for Contemporary Studies, San Francisco, California, USA.

Ostrom, E. 2000. Collective action and the evolution of social norms. Journal of Economic Perspectives 14(3):137-158. http://dx. doi.org/10.1257/jep.14.3.137

Punjab Irrigation and Drainage Authority (PIDA). 2014. Water charges (abiana). PIDA, Lahore, Pakistan. [online] URL: http:// pida.punjab.gov.pk/abiana

Qureshi, A. S., P. G. McCornick, M. Qadir, and Z. Aslam 2008. Managing salinity and waterlogging in the Indus Basin of Pakistan. Agricultural Water Management 95(1):1-10. http://dx. doi.org/10.1016/j.agwat.2007.09.014

Rege, M., and K. Telle. 2004. The impact of social approval and framing on cooperation in public good situations. Journal of Public Economics 88:1625-1644. http://dx.doi.org/10.1016/ $\underline{\text { S0047-2727(03)00021-5 }}$

U1 Hassan, M. M. 2009. The conception, design and implementation of IMT in Pakistan's Punjab: a public policy reflection. South Asian Water Studies 1(2):132-142.

World Bank. 2010. Implementation completion and results report on the sector development policy loans in the amount of $J P ¥ 11,780,000,000$ (US\$ 100 million equivalent) and in the amount of US\$100 million to the Islamic Republic of Pakistan for Punjab irrigation sector development. World Bank, Washington, D.C., USA. 


\section{Appendix 1. Game Implementation Protocol.}

\section{(Explain experiment goals)}

Thank you for being here and giving us a significant portion of your time. The simulations we will do today are part of a larger study across Punjab to understand the different ways in which canal water and groundwater are important to farmers. The results of the study will help us to plan better investments in Pakistan's irrigation system, which in turn can help improve the access that you all enjoy to irrigation water.

\section{(Explain simulations)}

Today we are going to do a set of simulations designed to capture some of the experience of using water to irrigate crops within your own farm over a number of seasons. I'll explain how the simulation is done, and then we'll all do a short practice run to learn the simulation. After that, we'll do two full simulations under some different scenarios. In total, this should take about 3 hours, with a few breaks in the middle. You'll each be provided a box of sweet pastries as a thanks for giving us your time, but there is one more thing. We'd like you all to do your best to generate resources in your watercourse in the simulation, so there will be a bonus (an extra box of pastries) for the $1^{\text {st }}$ place finisher in each of the simulations - that is, the farmer who generates as close to the maximum wealth as they can.

In this simulation you'll have a simple farm to take care of. Your farm has an offtake from the distributary/canal that is designed to provide all the water it needs, and if there is enough water in the distributary, you'll receive that amount of water in each turn. If there isn't enough water, you'll receive less than that, or perhaps none at all, if the distributary has dried up before it reaches your offtake. Now, this simulation is simple, and we aren't doing in real time - each turn in the simulation is like a whole season, and the amount of water you get is like the amount of water you get across the whole season. You can think of the amount that you are allocated for the season as being like your warabandi turn, but added up over the whole season. Just like with warabandi, the more water that enters your watercourse (i.e., the longer time each turn you have water coming in), the less is available to enter watercourses downstream. Each simulation has a total of 10 turns, so you could think about it as stepping through 10 separate seasons of irrigating in your watercourse.

The resources you generate in your watercourse in each turn depend on two things - how much water is coming into the watercourse, and how well the watercourse is maintained. If there isn't much water coming in - like when the distributary is dried up - you won't generate much resource. Some turns will have lots of water, some turns will have less. In the same way, if your watercourse isn't maintained well - a s if there is a lot of silting or seepage - you won't generate much resource. In both cases - for maintenance and water in - the resources you get follow an ' $S$ ' shape. That is, when you have very low maintenance, improvements don't lead right away to big changes; the same is true when water is really low. In the same way, when you have really high maintenance, or water close to the total demanded by your watercourse, adding more doesn't change your resources much. It is in the middle, in between those extremes, that adding more water or improving maintenance matters the most. 
In the simulation, you'll be able to do several different things each turn to try to generate more resources.

The first thing you can do is to lobby for your offtake to be higher. This will cost you some of your resources, but will mean that you will have more water coming into your watercourse in the turns that follow, if sufficient water reaches your offtake. Lobbying in the simulation isn't illegal - it just means that you get more of the water passing your farm, and less moves downstream.

The second thing you can do is invest in maintaining your watercourse. You can think of this as making better use of the water you have. If the maintenance level in your watercourse is low, spending resources to improve maintenance can lead to more resources generated.

The other thing you can do is ask for the offtake of other farmers to be reduced. This costs resources as well, but can help make sure that water makes it all the way to your offtake in turns where there is less water to go around. Even if you are receiving all of the water that you are allocated, you can still protest - perhaps if someone that you know downstream of you is not receiving enough, and you know of someone upstream of them that is getting more than they need. One thing that is really important to note is that protesting is anonymous - none of the other players will know who, if anyone, protested their allocation. So, you don't have to worry about what someone might think if you protested.

In sum, there are three things to think about - how much water do you need, how much water are you allocated, and how much water are you getting. If you aren't allocated as much water as you need, lobbying for more can help you get what you need. If you are allocated enough, but aren't getting enough, protesting the allocation of farmers upstream could help more water to reach you. And finally, if you are getting the water you need, but aren't generating much resources, it may be worth investing in maintaining the watercourse.

Each of these actions has a unit cost - XXX to ask for a YY unit increase in offtake, or XXX to improve maintenance by YYY\% - and you can do each of them as much or as little as you like during your turn, as long as you have the resources to pay. We'll look in a moment at exactly how this will happen during the simulation.

\section{(Explain departures from real experience)}

First though, we'd like to acknowledge that this is a lot simpler than what it is like to manage a real farm. There are many more decisions to be made in a real farm, and they get made at all different times across a season - not just at once. The simulation we've designed here is meant to help us understand in a very short time how different decisions get made at the farm level, and we hope you will find the experience useful.

\section{(Explain farmer screen)}


Now, let's take a look at the simulation. What you see here is the screen you'll see at each one of your turns. The bar across the top of the screen represents the watercourse, before and after water is offtaken for your farm, and lets you visualize how much of the overall water left in the watercourse for the season is used in your farm. The numbers to the left and the right of your offtake are the number of units of water in the watercourse before and after your offtake.

To the right of your offtake you can see how much water it is designed to take, and how much you actually got. If there isn't enough water in the watercourse, you won't get as much as you are allocated. Below your offtake, you can see a picture of a field, representing all the cropland in your farm. The numbers below the field tell you how much water the cropland in your farm demanded, and how far short of this demand the actual amount of water delivered fell.

In the lower right corner, you can see one last set of numbers. This tells you how much resource your farm generated this turn, how much resource you have overall (built up from previous turns), and what the level of maintenance in your farm is.

Your three actions are the buttons at the lower left. If you click on 'Lobby', you'll be able to pay resources to increase the offtake your farm is designed to receive. As you click the '+' button, you'll see how much total water you'll be receiving, and how much it will cost you in this turn to lobby for it. If you want to decrease the amount you are asking for, click the '-' button. When you have the amount you want, click 'Go', and your offtake will be adjusted for your next turn.

If you want to request that the offtake of another farmer be reduced, click on 'Protest'. You'll need to select the farmer from the list, and then, just like with 'Lobby', the '+' and '-' buttons let you choose how much of a change to ask for, and the 'Go' button will confirm it. The total cost to you will be shown at the bottom.

Finally, if you want to improve how water is used in your farm, click 'Maintain'. You'll see a slider showing the current level of maintenance in your farm. You can move the slider directly, or use the '+' and '-' buttons to select the level of maintenance you want to reach, and you'll see the total cost to you at the bottom. Once again, click on 'Go' to make those changes and invest in maintaining your farm.

You don't need to spend all of your wealth in one turn, and it may not be the best thing to do. Sometimes spending wealth on increasing your water offtake or maintenance will pay for itself in an increase in resources, but not if you're already getting all that you need, or if your channel is well maintained. You'll have to decide how best to use your resources.

When you've made all the choices you want, click on 'Next Farmer' and pass the tablet to the farmer downstream of you in the simulation.

While you are waiting for your next turn, feel free to talk with the other players in the game, EXCEPT please do not discuss your game decisions with them.

And finally, remember your goal - to maximize your overall wealth. 
We will do a short practice now to get a feel for the simulation. Before we start, are there any questions about the simulation that I can answer?

(Explain again simulation schedule - short practice followed by 2 full simulations)

Ok, we'll start with a quick practice simulation and then take a short break. Following that, we'll begin our two full simulations, taking a short break in between.

\section{(Practice simulation)}

In the practice, we've given you a large amount of resources to work with, so you can experience what the different options do. In the actual games, your resources will be much more limited, so take care to see what each action does.

(For each farmer during the practice, highlight what would happen if they did different things. If they change their allocation, their allocation would come closer to their demand. If they change the allocation of farmers upstream, then more of the available water would reach them. If they change the allocation of farmers downstream, they wouldn't see any change, but farmers further downstream would have more water available. If they maintain their properties, they will generate more resources with the water that they obtain.)

\section{(Simulation 1)}

\section{(Simulation 2)}

Ok, now the conditions in this simulation are a little different. There has been an investment to improve the canal system, and instruments have been installed that let you know how much water is available throughout the system.

In between turns, you can see what else is happening in the other farms along the watercourse. A screen will appear at the end of the cycle and before each farmer's turn that displays information about what happened in all farmers' turns during the last turn. It will display how much water entered the watercourse during the last turn, as well as how much water each farmer was allocated and how much he or she got.

Other than that, the simulation is done just as before.

(At each information screen, highlight the information provided. i.e., Overall there was XXXX units in the distributary. Player $X X X X$ had a total area of $W W W W W$, was allocated $Y Y Y Y$, and got ZZZZ. , etc.)

\section{Responding to questions}

Regarding Lobbying: 
In the simulation, you are using your wealth to have the size of your outlet/mogha increased. There aren't any rules in the simulation that say you can't - it's perfectly allowable. The only consequence is that there is less water available for others downstream. 
Appendix 2. Functional form and parameters for resource generation.

The function for resource generation, $\mathrm{R}$, is given by:

$$
R=a_{0} A\left(\frac{a_{1} \exp \left(a_{2}(X-1)\right)}{1+a_{1} \exp \left(a_{2}(X-1)\right)}\right)\left(\frac{a_{3} \exp \left(a_{4}(V-1)\right)}{1+a_{3} \exp \left(a_{4}(V-1)\right)}\right)
$$

where $\mathrm{A}$ is the area of the farm (fixed at 100ha for all players in this experiment), $\mathrm{X}$ is the level of maintenance on the watercourse, $\mathrm{V}$ is the fraction of water demand met, and $\mathrm{a}_{\mathrm{i}}$ are constants given below

\begin{tabular}{llrr} 
& Unit & \multicolumn{2}{c}{ Value } \\
\hline a0 & - & 60 \\
a1 & - & 2 \\
a2 & - & 6 \\
a3 & - & 2 \\
a4 & - & 6
\end{tabular}


Appendix 3. Descriptive statistics for Game and Player variables.

\begin{tabular}{|c|c|c|c|c|}
\hline Variable & Description & Observations & Mean & $\begin{array}{c}\text { Standard } \\
\text { Deviation } \\
\end{array}$ \\
\hline Protest Receipt & Protest receipt by player in current round & 6510 & 9.105223 & 18.5486 \\
\hline Protest & $\begin{array}{r}\text { Protest spending by player in current } \\
\text { round }\end{array}$ & 6510 & 8.579109 & 21.30222 \\
\hline Lobby & $\begin{array}{l}\text { Lobby spending by player in current } \\
\text { round }\end{array}$ & 6510 & 15.71782 & 17.89735 \\
\hline Maintenance & $\begin{array}{r}\text { Maintenance spending by player in } \\
\text { current round }\end{array}$ & 6510 & 301.4286 & 306.6628 \\
\hline Age & Age & 6510 & 38.73149 & 15.31205 \\
\hline Education Level & Education Level & 6510 & 3.074808 & 1.702509 \\
\hline KP Chairman & KP Chairman & 6510 & 0.1751152 & 0.3800948 \\
\hline Command Area & Home Watercourse Command Area & 6510 & 418.3653 & 404.7047 \\
\hline Property Size & $\begin{array}{l}\text { Home Property Size } \\
\text { Farm Location along home watercourse }\end{array}$ & 6510 & 19.28414 & 24.45693 \\
\hline Farm Location & $(0=$ head, $1=$ tail $)$ & 6510 & 0.5166696 & 0.2967609 \\
\hline Site & Site & 6510 & 0.483871 & 0.4997782 \\
\hline Allocation_t $\mathrm{t}-1$ & Allocated water of player in prior round & 6510 & 337.8747 & 35.3278 \\
\hline Use_t -1 & $\begin{array}{r}\text { Water prior } \\
\text { Change in Allocated Water, prior to }\end{array}$ & 6510 & 297.2449 & 102.1109 \\
\hline$\Delta$ Allocation & current & 6510 & 7.772811 & 23.09535 \\
\hline$\Delta$ Use & Change in Used Water, prior to current & 6510 & 3.160215 & 117.3576 \\
\hline Protest Return & Return to protest, prior & 6510 & 1.292425 & 19.38637 \\
\hline $\begin{array}{r}\text { Wealth } \\
\text { Maintenance }\end{array}$ & Wealth & 6510 & 1058.461 & 1376.242 \\
\hline $\begin{array}{r}\text { Level } \\
\text { Resource }\end{array}$ & Maintenance Level, current & 6510 & 0.8511444 & 0.1102227 \\
\hline Generated & Resource Generated, current & 6510 & 970.9682 & 685.3053 \\
\hline
\end{tabular}

